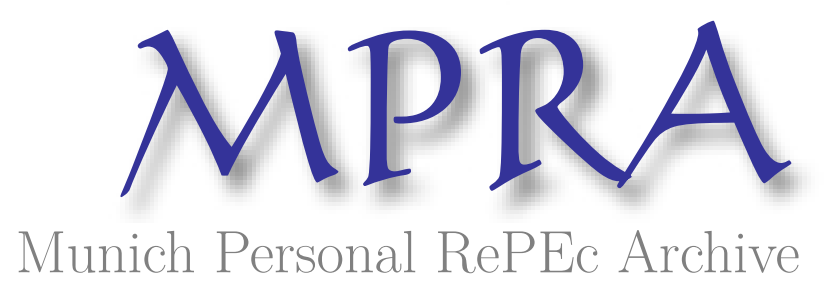

\title{
Promoting Competition or Helping Less-Endowed? An Experiment on Collective Institutional Choices under Intra-Group Inequality
}

Kamei, Kenju

Department of Economics, Bowling Green State University

20 June 2014

Online at https://mpra.ub.uni-muenchen.de/56774/

MPRA Paper No. 56774, posted 22 Jun 2014 04:32 UTC 


\title{
Promoting Competition or Helping Less-Endowed? An Experiment on
}

Collective Institutional Choices under Intra-Group Inequality

\author{
Kenju Kamei \\ Department of Economics, Bowling Green State University \\ Email: kenju.kamei@gmail.com,kkamei@bgsu.edu
}

This version: June, 2014

\begin{abstract}
:
Unequally-distributed resources, whether people's income or competence, are ubiquitous in our real world. Whether to promote competition or to lead to a more equal environment is often in question in societies or organizations. With heterogeneous endowments, we let subjects collectively choose whether to have a competitive lottery contest - where only one individual in a group wins and receives an award, generating a greater income inequality - or to have a public good that benefits the less-endowed to a greater degree. Our data indicates that highly-endowed individuals contribute little when the public good is selected. The majority of subjects, however, vote in favor of having a public good, contrary to the standard theory predictions. In addition, a belief elicitation task shows that they expect payoffs to be more equally distributed under the public good regime than under the contest regime. Moreover, the subjects' preferences between the two regimes are little affected by their risk attitudes or the size of awards in competition. These suggest that people's institutional choices are driven more by their income inequalityaverse preferences.

JEL classification: C92, D04, D63, D74, H41
\end{abstract}

Keywords: heterogeneity, experiment, cooperation, competition, public goods, inequality 


\section{Introduction}

The prevalence of heterogeneous resources - the unbalanced distribution of incomes or capacities in people - is one of the most fundamental features of organizations and societies (e.g., Stiglitz 2012, Piketty 2014). For example, there are wide income gaps and differences in the living standards within a society. The Gini coefficient of household disposable incomes is on average 0.31 even in OECD countries. ${ }^{1}$ Similarly, in organizations, the performance and competence of workers is diverse even if they have similar work experiences, which may create salary gaps among them. Although the heterogeneity of resources has some positive aspect, it also has negative aspects. On the one hand, the heterogeneity of resources may contribute to efficiency as it stimulates competition among people. But on the other hand, it often results in serious intra-group conflicts because of the inequality. We then face a difficult collective decision to make: whether to promote competition for the sake of efficiency or to lead to a more equal environment by offering some redistribution mechanism even though efficiency may be sacrificed.

For instance, in a firm, wage inequality may be helpful in securing or attracting highly skilled workers, but it may decrease work motivation among low-skilled workers and may also result in disharmony among workers in interdependent work (e.g., Akerlof and Yellen 1998, Trevor et al. 2012). Although incentive schemes such as tournaments that are used in firms may contribute to higher productivity of workers and thus more efficiency in managing a firm in the management's view, such competition may lead to uncooperative behaviors among workers. Treatments to compress pay inequality or their heterogeneous competence, such as voluntary mentoring and education programs, may help them maintain harmony; but these treatments may demotivate high-skilled workers if they want high compensations. For another example, income inequality increases anti-social behavior such as violent crime in societies (e.g., Kelly 2000). Voluntary activities in charitable organizations are supported through the reduction of the tax requirement in order to alleviate poverty in a society, which would help shrink the income gap and create a more fair society; but it may displease those with wealth who would lead the economic growth of the society as they cannot enjoy the benefits. Also, the presence of such redistribution mechanisms may reduce people's incentives to work.

1 See OECD Factbook 2013 (DOI : 10.1787/18147364). 
Therefore, whether to promote competition for efficiency, though it may exacerbate conflicts, or to lead to a more equal environment and support the less-privileged is often in question in situations where resources vary by people. In the recent decades, economists have actively studied people's collective institutional choices using laboratory experiments. However, despite the tremendous impact that the results of collective choices may have on societies or organizations as mentioned above, little attention has been paid to how people collectively choose between competitive and cooperative institutions within a group when there exists heterogeneity in their endowments.

Exploring behavioral principles for people's collective choices on this topic is not straightforward, however. First, past extensive experiments have found that some individuals have other-regarding preferences such as inequality aversion (see Fehr and Schmidt (2006) for a survey). For example, some of the individuals may enjoy some higher non-material gains if their payoffs are similar to each other. Therefore, we cannot infer their institutional choices only from their material incentives. Second, recent experiments show that egalitarian subjects - those who prefer fair distribution of payoffs - are more likely to stay away from competitive environments in real-effort experiments (e.g., Bartling et al. 2007, Balafoutas et al. 2012). ${ }^{2}$ The more egalitarian preferences they have, the less likely they may be to support competitive institutions. The voting decisions of the egalitarian individuals nonetheless may depend on the degree of material incentives under the competitive regime. A person, even if she is strongly income inequality averse, might support a competitive institution if her potential benefits from competition are sufficiently high. In addition, their voting decisions may also depend on their assigned endowments as their material or non-material incentives differ by the endowment. Third, a rich experimental literature has found that in situations where their resources are unbalanced, those vested with larger (smaller) resources behave more (less) selfishly (e.g., Buckley and Croson 2006, Chan et al. 1996, Cherry et al. 2005, Maurice et al. 2013). This tension between the higher and lesser endowed members may be severe enough for them to collectively choose a more competitive environment if there is such an opportunity.

We conduct an experiment in order to study people's collective institutional choices between a competitive scheme versus a public good that helps the less-endowed more when their

\footnotetext{
${ }^{2}$ The subjects made choices between a tournament and a piece rate scheme in these two papers.
} 
resources are unequally distributed. A novel feature of our experimental design is to let subjects collectively select one from two fundamentally different institutions under each of which the same endowments can be used. Group size is five. Endowments are unbalanced across subjects; they are randomly assigned to them at the onset of the experiment. Specifically, one member receives an endowment of 50 points, two members receive that of 20 points and the remaining two receive that of 10 points. Each group then collectively chooses one out of two regimes by voting: a public good regime and a competitive lottery contest regime. A group has a social dilemma when it collectively implements a public good. Under this regime, each member makes allocation decisions between their private account and public account using their own endowments. They get one point for each point they allocate to their private account. The total contributions to their public account are doubled and are then redistributed among the members. The distribution rule is that the smaller endowment they have, the more they receive from the public account. By contrast, members compete for an award of 50 points or 110 points if a group selects a lottery contest regime. Under this regime, each member decides how many points they allocate to their lottery accounts. The more points a subject assigns to the account the more likely she is to win the competition and receive the award. Only one member wins the competition in the contest regime. Their interaction under a collectively selected regime is one-shot. ${ }^{3}$ Their beliefs on the allocation decisions of the other four group members under collectively selected regimes and their risk attitudes are elicited in order to explore driving forces behind their institutional choices.

As consistent with findings of related studies, our data indicates that a significantly smaller proportion of the subjects with the highest endowment, compared with the other subsets of the subjects, contribute positive amounts to the public account in the public good regime. However, surprisingly, around 70 to $80 \%$ of the entire subjects prefer having a public good, contrary to the standard theory assumption of all being selfish. The percentages of the subjects' support for a public good are little affected by the size of award (50 or 110) in the other regime. Moreover, a comparison of the distributions of realized payoffs within groups indicates that the average Gini coefficients in the public good regime are significantly smaller than those in the lottery contest regime. An exploration of the subjects' beliefs reveals that they also on average

\footnotetext{
${ }^{3}$ This experimental setup is used to obtain data without reputation effects.
} 
believe that their payoffs are more equally distributed in their groups if a public good regime is selected. Furthermore, we also find that the subjects' risk attitudes are statistically similar between those who vote for a public good and those who vote for a lottery contest. These results suggest that the subjects' collective institutional choices are driven more by their income inequality-averse motives. This implies that people may collectively decide not to implement a competitive policy if it enlarges inequality among the members when their resources are unequally distributed even if it can be an efficiency-enhancing policy on the whole.

The rest of the paper proceeds as follows: Section 2 describes our experimental design. Section 3 provides the theoretical predictions and hypotheses. Section 4 reports results, and Section 5 discusses our results and concludes.

\section{Experimental Design}

The experiment consists of two phases. The first phase is a stage in which endowments are randomly given to subjects. The second phase is a voting decision stage followed by an allocation stage. Subjects collectively make one-time policy implementation decisions and individual allocation decisions in Phase 2. Our study consists of (a) two main treatments in which either a public good or a lottery contest is endogenously selected by subjects' votes and (b) one control treatment in which a public good is exogenously imposed in Phase 2 (Table 1).

At the onset of Phase 1, subjects in all treatments are randomly assigned to a group of five individuals. We use a partner-matching protocol: the group composition does not change between Phase 1 and Phase 2. Phase 1 plays a role in generating an unequal distribution of endowments among members. In each group, one subject receives 50 points, two subjects receive 20 points, and the remaining two are given 10 points. The assignment of endowments is random: the probabilities with which they receive 50, 20 and 10 points are 1/5, 2/5 and 2/5, respectively. We refer to the set of subjects who are given 50, 20 and 10 points as their endowments as Sets $H, M$ and $L$, respectively.

In the two main treatments, the Low and High treatments - dubbed L and H, Phase 2 begins with subjects' voting decisions concerning whether to create a public good or to implement a lottery contest, contingent on two voting rules: an equal and a weighted voting rule 
(see Section 2.2). Subjects subsequently submit their beliefs on the other members' voting decisions. In order to avoid a hedging problem, the belief elicitation task is not incentivized. Also, we do not tell subjects about the presence of the elicitation task at the onset of the experiment. ${ }^{4}$ After that, the computer randomly assigns one of the two voting rules for each group. A public good or a lottery contest is then collectively implemented in accordance with the result of their votes; and each subject makes an allocation decision under a selected regime as explained in Section 2.1. (In the control treatment, which is called the Exogenous Public Good treatment, subjects do not vote on the two regimes; they make contribution decisions based on their endowments to their groups' public goods.) Once all subjects complete their allocation decisions, they submit their beliefs on the other four members' allocation decisions before being informed of the outcomes of the allocation stage. As in the first belief elicitation task, this elicitation task is also not incentivized. However, at the end of the experiment, just before they are informed of the outcome of the allocation decisions, all subjects are asked to answer incentivized questions concerning their risk attitudes (see Section 2.3). ${ }^{5}$ Fig. 1 is a schematic diagram of the experiment. We will explain each piece of the design in details below.

\subsection{Two Possible Regimes: The Target of Collective Choices}

The public good, one of the options of the vote, corresponds to goods and services, such as voluntary mentoring or education programs for employees in corporations, poverty alleviation programs in international organizations, or some redistribution mechanisms in societies. If a public good is created in a group, then each subject in the group simultaneously makes an allocation decision between their private account and the public account. Their contributions must be integers between 0 and their own endowments (50, 20 or 10). As usual in voluntary contribution game experiments, a subject gets one point for each point that she allocates to her private account. The allocation to the public account, by contrast, is doubled and redistributed among members: $25 \%$ of the amounts are given to each of the two Set $L$ subjects, $20 \%$ of them are given to each of the two Set $M$ subjects and $10 \%$ of them are given to the Set $H$ subject (note that $25 \% \times 2+20 \% \times 2+10 \%=100 \%$ ). In other words, the distribution rule is that the less

\footnotetext{
${ }^{4}$ They are instead told that some additional questions related to the experiment may be asked while the experiment is in progress and that their responses to these questions will not affect their payoffs.

${ }^{5}$ They are not told about the presence of this task at the onset of the experiment. They are instead told that some additional questions unrelated to the main part of the experiment may be asked.
} 
resource a member has, the more the member receives from the public account. This redistribution rule is often prevalent in the real world. For example, such funds in international organizations are often used to help less-developed countries. In a society, various policies such as public welfare assistance are generally used to help the poor. In a firm, voluntary "buddies" programs tend to help less-skilled workers more than highly skilled workers.

Suppose that a public good is put in place in a group and a member having an endowment $E_{i}$ contributes $C_{i}$ to the public good. Then, her payoff, $\pi_{i}$, is expressed as follows:

$$
\pi_{i}=\left(E_{i}-c_{i}\right)+\alpha_{i} \cdot 2 \sum_{j=1}^{5} c_{j}
$$

where $\alpha_{i}=.1$ if subject $i$ is a Set $H$ subject; $\alpha_{i}=.2$ if subject $i$ is a Set $M$ subject; and $\alpha_{i}=.25$ if subject $i$ is a Set $L$ subject. The first term, $E_{i}-c_{i}$, refers to the payoff of subject $i$ from her private account.

By contrast, when a lottery contest is collectively implemented in a group, subjects compete with the other four members for an award. Specifically, each member in the group simultaneously decides an allocation amount to their lottery account. The award is 50 points (110 points) and the competition is low (high) in the L treatment (the H treatment). Only one member in the group receives the award. Each subject in this regime can increase the probability of winning the competitive battle by raising their allocation amounts to their lottery account. Suppose that subject $i$ makes an investment of $x_{i}$ out of his endowment $E_{i}$ and also that the other four members allocate $X_{-i}$ in total to their lottery accounts. Then, subject $i$ 's probability of obtaining the award is $\frac{x_{i}}{x_{i}+X_{-i}} \cdot x_{i}$ must be non-negative and less than or equal to her endowment $\left(E_{i}\right)$. When all five members allocate nothing (i.e., $x_{i}=0$ for all $i$ ), then the award is randomly given to one of the members (i.e., each receives it with a probability of 20\%). They receive their remaining points after investment, $E_{i}-x_{i}$, as a part of their payoff. The competition in the lottery contest is also prevalent in our real world. For example, in organizations, workers' capacities or resources vary by employee as in our paper; and the more efforts they exert, the more likely they are to get promoted to a higher position. The chances of promotion, however, would negatively depend on the contributions of other workers in the firm as higher-ranked positions are limited. In competitions across countries for research and development, the chances that a national 
company succeeds in developing a new technology ahead of other companies depends on its relative investment amount of resources.

Once all subjects make their allocation decisions under one of the two regimes, they are asked about their beliefs on how other members made allocation decisions. Specifically, a Set $H$ subject is asked about his or her beliefs on the average allocation of the two Set $M$ subjects and that of the two Set $L$ subjects in her group. A Set $M(\operatorname{Set} L)$ subject is asked about his or her beliefs on (a) the allocation of the Set $H$ subject, (b) the allocation of the other Set $M(\operatorname{Set} L)$ subject and (c) the average allocation of the two Set $L$ (Set $M$ ) subjects in her group. These elicited beliefs are used in analysis to calculate each subject's perceived (expected) payoff under their collectively implemented regime. This information would be helpful in understanding causes of their individual voting decisions as discussed in Sections 3 and 4.

\subsection{Voting Rules}

Our study lets subjects vote under the two voting rules: a weighted voting rule and an equal voting rule and assesses the effects of voting power on their collective institutional choices as an additional analysis. ${ }^{6}$ This analysis is conducted as it is shown that collective institutional choices may differ by voting rule. For instance, Markussen, Reuben and Tyran (2014) have experimentally found that efficiency-enhancing inter-group competitive scheme is more likely to be selected in a set of three groups when an equal voting rule (i.e., a voting rule that imposes a policy if the majority of the three group members support it) is used, relative to when a group veto rule (i.e., a rule that imposes a policy if the majority of each group supports it) is used. Collective outcomes may differ by voting rule in our study as well because subjects' voting decisions may be affected by the heterogeneity of their endowments, considering that their incentives (material or non-material) under each regime may differ by the amount of endowments they are given.

In the $\mathrm{L}$ and $\mathrm{H}$ treatments, at the onset of Phase 2, subjects vote on whether to have a public good or a lottery contest for each of the two scenarios: (1) the equal voting rule is used and (2) the weighted voting rule is used. After all subjects complete their decisions, they are

\footnotetext{
${ }^{6}$ Weighted voting rules are often used in organizations or societies (e.g., Leech 2002, Rapkin and Strand 2006). Examples include collective decision-making in IMF and IBRD or in shareholder meetings of a corporation.
} 
subsequently asked about their beliefs concerning how the others in their groups voted before they are informed of its collective outcomes. ${ }^{7}$ The two voting decisions are incentive compatible. Once all subjects submit their voting decisions and the subsequent questions on their beliefs, the computer assigns either the equal or weighted voting rule for each group with a probability of $50 \%$ each. Then, one of the two voting decisions made by each subject is cast as their vote. ${ }^{8}$ When the weighted voting rule is assigned to a group, the voting power of subject $i$ is $E_{i} / 110$. Here, 110 yields from $50+20+20+10+10$ (the sum of endowments in a group).

Consequently, the distribution of voting power among the members is unequal: the more resources a subject has, the more his or her vote influences the outcome. The voting power of the Set $H$ subjects is the largest. However, it is not possible for them alone to decide the adoption of the policy by their votes, as their voting power equals $50 / 110$, which is not greater than 0.5 , in their groups. Therefore, the votes cast by the subjects belonging to the Sets $M$ and $L$ also influence each group's collective decision, although they influence the result of their collective decision less than those of the Set $H$ subjects do. When the equal voting rule is assigned to a group, then, the voting power is one-fifth for each subject. Hence, the standard majority rule determines each group's regime, either a public good or a lottery contest.

\subsection{Elicitation of Risk Preferences}

Once all subjects submit their beliefs on the other four members' allocations to either a public account or a lottery account, they are subsequently asked to answer questions concerning risk attitudes. The questionnaire on risk attitudes consists of the ten questions used in Holt and Laury (2002). We include this task in order to study whether their voting preferences between the two regimes are affected by their risk attitudes as discussed in Section 3.

\footnotetext{
${ }^{7}$ For example, each Set $M$ subject is asked about their beliefs on the voting decision made by their Set $H$ subject, the decision made by the other Set $M$ subject, and the decisions made by the two Set $L$ subjects for each of the two voting rules.

${ }^{8}$ This kind of strategy method is commonly used when there is a need to obtain incentive-compatible decisions under each of many possible conditions. For example, in Fehr, Herz and Wilkening (2013), who study the value of individual decision rights in a principal-agent framework, a principal first decides whether or not to delegate a decision right to an agent; and then, before the principal and the agent are informed of the delegation decision, both players choose their effort levels as well as their beliefs about their matched partners' effort levels, contingent on whether they have a right to decide, using a strategy method. In Dal Bó, Foster and Putterman (2011) and Kamei (2014), who study the impact of endogenous decision-making on people's pro-social behavior, all subjects make voting decisions on implementation of a policy before implementation conditions are assigned to their groups. After their voting decisions, the computer randomly assigns either an endogenous or exogenous condition to each group.
} 


\section{Theoretical Predictions}

A group has a collective action dilemma if a public good is selected in that group. This is because the MPCR (marginal per capita return) is $2 \cdot \alpha_{i}$, which is less than 1 for each subject, as shown in Eq. (1). Therefore, according to the standard theory, contributing nothing to their public account is a strictly dominant strategy for each group member. The Set $H$, Set $M$ and Set $L$ subjects obtain 50 points, 20 points and 10 points, respectively, as their payoffs under Nash Equilibrium (NE).

By contrast, if a lottery contest is collectively implemented in a group, then the group members can enjoy some gains, regardless of whether they are risk averse. Suppose that each member in a group is risk neutral. Then, the utility function of a subject is proportional to his or her expected payoff. The expected payoff of subject $i, E\left[\pi_{i}\right]$, is calculated by:

$$
E\left[\pi_{i}\right]=\left(E_{i}-x_{i}\right)+\frac{x_{i}}{x_{i}+X_{-i}} z .
$$

Here, $z=50(110)$ in the $\mathrm{L}(\mathrm{H})$ treatment. Under this assumption, we find that each member, regardless of their endowment, chooses to allocate 8 points to their lottery account in order to maximize their expected payoff in the $\mathrm{L}$ treatment (see Appendix A.1). They can raise their expected payoff by 2 points in equilibrium in the L treatment. Optimal allocation amounts differ by their endowment in the $\mathrm{H}$ treatment. The Set $H$, Set $M$ and Set $L$ subjects allocate 21 points, 20 points and 10 points, respectively, to their lottery accounts in equilibrium. As a result, the probability of winning the competitive battle is the highest (the lowest) for the Set $H$ subjects (Set $L$ subjects). Their expected payoff of each category of subjects is higher in equilibrium in the $\mathrm{H}$ treatment than in the $\mathrm{L}$ treatment (see Table 1). The standard theory therefore predicts that subjects prefer to have the lottery contest in both the $\mathrm{L}$ and $\mathrm{H}$ treatments under the assumption of the risk-neutral preference.

The advantage of the lottery contest over the public good does not change even if we instead assume that subjects are risk-averse. This is because they can allocate amounts as small as possible to the lottery accounts and also because there is also an option for them to at least keep their own endowments by allocating nothing to the accounts but at the same time still have 
a chance of receiving an award in case all of the other four members allocate zero points to the lottery accounts.

\section{Prediction 1: Standard Theory Predictions}

Subjects allocate nothing to their public accounts when public goods are imposed in their groups. By contrast, they enjoy positive expected gains when lottery contests are imposed. They therefore vote in favor of having a lottery contest in their groups.

However, experiments in recent decades have found that people have other-regarding preferences, such as income inequality aversion (e.g., Fehr and Schmidt 1999, Bolton and Ockenfels 2000) and reciprocity (e.g., Rabin 1993, Dufwenberg and Kirchsteiger 2004, Falk and Fischbacher 2006). These preference models predict that some subjects contribute positive amounts to their public accounts and thus some of them enjoy payoffs higher than their own endowment amounts under the public good regime. As a result, their preferences between the two regimes may be different from Prediction 1. Suppose that subjects have income inequalityaverse preferences. For simplicity, we assume that subject $i$ has the following utility function:

$$
u_{i}\left(\pi_{i} \mid \pi_{-i}\right)=\pi_{i}-\mu_{i} \cdot \frac{1}{N-1} \sum_{j=1}^{N}\left(\pi_{j}-\pi_{i}\right)^{2} .
$$

Here, $\mu_{i}$ is utility weight of subject $i$ on inequality and $N$ is group size $(N=5) .{ }^{9}$ Subjects are assumed to be heterogeneous: $\mu_{i}$ differs by subject. As illustrated in Appendix A.2, the mutual full free-riding equilibrium (i.e., $c_{i}=0$ for all $i$ ) no longer occurs for broad ranges of $\mu$. Moreover, the income inequality-aversion model predicts that more Set $H$ subjects, relative to Set $L$ subjects, allocate positive amounts to their public accounts regardless of the decisions of the Set $L$ or Set $M$ subjects as the endowments of the Set $H$ subjects are much higher than those of Set $L$ subjects. The inequality-averse model also suggests the conditional cooperative behavior of the Set $L$ subjects and the Set $M$ subjects. This is because the Set $L$ subjects (the Set $M$ subjects) do not like inequality between themselves and the other Set $L$ subjects (the other Set $M$ subjects) or the Set $M$ subjects (the Set $L$ subjects). It is also because the Set $L$ subjects (the Set $M$ subjects) want to avoid having inequality with the Set $H$ subject when Set $L$ subjects (Set $M$ subjects) obtain high payoffs thanks to the others' decisions.

\footnotetext{
${ }^{9}$ A similar utility function is used in Chen and Kamei (2014). The use of a quadratic form, instead of the prominent functional form proposed by Fehr and Schmidt (1999), is due to its tractability.
} 
In the lottery contest regime, only one individual in a group wins a large award (50 or 110). A subject therefore can incur a large utility loss resulting from a greater income inequality in this regime if $\mu$ is high enough. Thus, this model predicts that some subjects - strongly inequality-averse subjects (i.e., those with sufficiently large $\mu$ ) - vote for a public good.

\section{Prediction 2: Predictions Based on the Income Inequality-Averse Preferences}

(a) Strongly income inequality-averse subjects contribute positive amounts to their public accounts. (b) More Set $H$ subjects, relative to Set L subjects, contribute positive amounts to their public accounts, regardless of the decisions of the Set $M$ and Set L subjects. (c) The contribution decision of a Set L subject (a Set M subject) is conditional, dependent on the contributions of the others: it is positively propositional to his or her beliefs on the contribution decision of the Set $H$ subject, the contribution decision of the other Set L subject (the other Set M subject), and the average contribution decision of the two Set M subjects (the two Set L subjects). (d) Those with sufficiently large $\mu$ vote in favor of a public good, rather than a lottery contest.

Note that reciprocity models also predict that some subjects allocate positive amounts to their public accounts and that therefore some of them vote in favor of the public good. Their motive of cooperation with other members is different, however: it is positive reciprocity resulting from kind intentions of the other members. The reciprocity models therefore predict strong conditional cooperative behavior of the Set $H$ subjects that is similar to that of the Set $M$ and Set $L$ subjects.

There is alternative possibility that subjects' risk preferences drive their institutional choices even when subjects have social preferences. The distribution of a subject's possible payoffs substantially differs between the two regimes. The range of his or her possible payoffs is larger in the lottery contest regime: a higher payoff is possible, but they obtain nothing from their lottery accounts if they lose the competition. Especially, the lottery contest regime in the $\mathrm{H}$ treatment generates a higher expected return but is very risky as the subjects need to allocate more amounts to their lottery accounts in order to win the competition as shown in Table 1. Even if they achieve high enough expected payoffs in the lottery contest regime that are comparable to those in the public good regime, more risk-averse subjects may vote in favor of the public good.

Prediction 3: Risk Preferences and Voting Decisions 
More risk-averse (risk-loving) subjects vote for a public good (a lottery contest).

We can test Prediction 3 by using the elicitation task regarding risk attitudes (Holt and Laury 2002). This task consists of ten questions, each of which asks subjects to choose an option between a risky lottery and a safe lottery. We use the number of risky options chosen by a subject (which we denote as $r \in\{0,1,2, \ldots, 10\}$ ) as a proxy of his or her risk preference. If Prediction 3 holds, then the average $r$ of those who vote for a public good should be significantly smaller than that of those who vote for a lottery contest.

Nevertheless, Prediction 3 may not hold, as subjects under the public good regime may incur some additional psychological cost when the other members do not contribute to their public accounts, and they may therefore want to avoid having the public good. This cost stems from people's betrayal-averse preferences and would not be present under the contest regime. Some recent studies find that people are less likely to take a risk by sending money to their matched trustees in trust games, compared with their risk-taking behavior in structurally identical decision tasks (e.g., Bohnet et al. 2008, Bohnet and Zeckhauser 2004). Even a subject whose preference is shown to be strongly risk-averse by the risk elicitation task may vote in favor of a lottery contest regime if his risk premium due to betrayal aversion is sufficiently high.

\section{Results}

Ten sessions, four per each of the two main treatments and two for the control treatment, were conducted at University of Michigan in Ann Arbor in April and May, 2014. The experiment was programmed in ztree (Fischbacher 2007). Almost all subjects were undergraduate students there. They were recruited via solicitation emails using a recruiting website, ORSEE (Online Recruitment System For Economic Experiments). No subjects participated in more than one session. No communication was allowed during the sessions. Experimental sessions lasted on average one to one and a half hours, and subjects earned on average \$22.39 (part of it was a participation fee of \$5) for their participation. Neutral framing was used in all instructions and experiments. ${ }^{10}$ In this section, we overview the subjects' institutional choices and their subsequent allocation decisions. At the same time we explore the

\footnotetext{
${ }^{10}$ For instance, the terms "group fund" and "allocation" were used instead of "public good" and "contribution," respectively, in the public good regime. Instructions are available from the author upon request.
} 
driving forces that are behind these decisions using data from additional tasks, such as their beliefs on the other members' allocation decisions.

Table 2 reports subjects' voting decisions and their collective vote outcomes. We find that a strikingly large portion of subjects, more than $70 \%$ of them in total, voted for a public good under each of the two voting rules, contrary to Prediction 1, which was based on standard theory (see the "Total" row in Table 2). The high percentages of support for a public good are statistically similar between the L and $\mathrm{H}$ treatments, even though their expected payoffs predicted under the other voting option (a lottery contest) substantially differ between the two treatments as shown in Table 1. In addition, the subjects' voting decisions are little affected by voting rule. ${ }^{11}$ The last observation is not surprising as even in the weighted voting rule the voting power of the Set $H$ subjects is less than $50 \%$ and a vote cast by any category of subjects affects their collective decisions to some degree.

A closer look at the voting data reveals that around half of the Set $H$ subjects prefer having the public good whereas a larger fraction of the Set $L$ or Set $M$ subjects vote for the public good in both the L and $\mathrm{H}$ treatments. A regression analysis, shown in Appendix Table B.1, confirms that the smaller endowment the subjects are assigned, the more likely they are to vote for a public good. ${ }^{12}$ The significantly different distribution of individual votes by endowment leads to a significant difference in their collective vote outcomes between the equal and weighted voting rules. We find that a public good regime is significantly more likely to be collectively chosen with the equal voting rule than with the weighted voting rule. ${ }^{13}$

\section{Result 1: Voting Decisions and Collective Vote Outcomes}

Around $70 \%$ to $80 \%$ of the subjects vote for a public good. The smaller endowments that they are assigned, the more likely they are to vote for a public good. Public goods are more likely to be

\footnotetext{
${ }^{11}$ The number of votes for a public good under the equal voting rule (102 out of 140 votes) is not significantly different from that under the weighted voting rule (98 out of 140 votes) according to a two-sample z-test of proportion ( $p$-value $=.597$, two-sided $)$.

${ }^{12}$ The regression analysis also indicates that female subjects are significantly more likely than male subjects to vote for a public good in the $\mathrm{H}$ treatment, but not in the $\mathrm{L}$ treatment. The lottery contest in the $\mathrm{H}$ treatment is more competitive due to a high award $(z=110)$. The result that women tend to stay away from competition is consistent with the findings of past studies (e.g., Niederle and Vesterlund 2007).

${ }^{13}$ The number of vote outcomes having a public good under the equal voting rule (24 out of 28 cases) is significantly different from that under the weighted voting rule (17 out of 28 cases) according to a two-sample z-test of proportion ( $p$-value $=.347$, two-sided). See the hyp. columns in Table 2 .
} 
collectively selected under the equal voting rule. The subjects' voting decisions are little affected by voting rule or by the size of award (50 or 110).

A plausible cause that may account for Result 1 is that people have some other-regarding preferences and believe that their members also do so as we discussed in Section 3. If this is the case, the payoffs from the public good regime that subjects believe they would obtain may be higher than their payoffs predicted by the standard theory under that regime and even higher than those in the lottery contest regime indicated in Table 1. Fig. 2 reports the average of subjects' perceived payoffs under their collectively selected regimes. Here, a subject's perceived payoff is calculated by using her own allocation decision and her beliefs on the other four members' allocation decisions. ${ }^{14}$ As shown in Appendix Table B.2, for the majority of the subjects in the $\mathrm{L}$ treatment of the public good regime, their perceived payoffs from the public good regime exceed not only their own endowment amounts ( $\pi^{P}$ in Fig. 2) but also their expected equilibrium payoffs calculated under the contest regime if selected ( $\pi^{L}$ in Fig. 2). ${ }^{15}$ The same does not hold for the subjects in the $\mathrm{H}$ treatment, however. Although the perceived payoffs in the public good regime are higher than $\pi^{P}$ for almost all subjects and they also exceed $\pi^{L}$ for the majority of the Set $L$ subjects, they are not higher than $\pi^{L}$ for all of the Set $H$ subjects and for around half of the Set $M$ subjects.

A comparison between the subjects' perceived payoffs between the two regimes also provides a clear difference in their material incentive between the subjects (Appendix Table B.3). The Set $L$ subjects on average believe that they would receive significantly higher (expected) payoffs under the public good regime in both of the $\mathrm{L}$ and $\mathrm{H}$ treatments. By contrast, the Set $M$ subjects on average believe that they would obtain higher expected payoffs under the lottery contest (public good) regime in the $\mathrm{H}$ (L) treatment. The Set $H$ subjects on average believe that their expected payoffs would be higher under the lottery contest regime in the $\mathrm{H}$ treatment; but their perceived payoffs are almost identical between the two regimes in the L treatment. These

\footnotetext{
${ }^{14}$ Eq. (1) or (2) is used for this calculation. For instance, a Set $M$ subject's perceived payoff in the public good regime is calculated by: $20-C_{M}+.2 \cdot 2 \cdot\left(C_{H}^{b}+C_{M}+C_{M}^{b}+2 C_{L}^{b}\right)$. Here, $C_{M}$ is the contribution of the Set $M$ subject, and $C_{H}^{b}, C_{M}^{b}$, and $C_{L}^{b}$ are the Set $M$ subject's beliefs on the contribution of the Set $H$ member, the contribution of the other Set $M$ member, and the average contribution of the two Set $L$ members, respectively.

${ }^{15}$ Contrary to this result, the average perceived payoff of the Set $H$ subjects in the public good regime is less than 52 in the L treatment (Figure 2(a)). This is due to one Set $H$ subject who contributed his or her full endowment to the public account and had a very low perceived payoff.
} 
results explain a part of Result 1 (the smaller endowments subjects are assigned, the more likely they are to vote for a public good); as those vested with smaller endowments, unlike the Set $H$ subjects, on average believe that they would be materially better-off under the public good regime. However, despite the clear difference in the material incentive, the subjects' actual voting decisions, including the ones by the Set $H$ subjects, are surprisingly very similar between the $\mathrm{L}$ and $\mathrm{H}$ treatments. This intriguing observation suggests that individuals' voting decisions are not merely driven by the level of their own (expected) perceived payoffs.

\section{Result 2: Perceived Payoffs between the Two Regimes}

In the L treatment, the Set L and Set M subjects, but not the Set H subjects, believe that they would obtain significantly higher (expected) payoffs under the public good regime than under the lottery contest regime. By contrast, in the H treatment, the Set H and Set M subjects (Set L subjects) believe that they would obtain significantly higher expected payoffs under the lottery contest (public good) regime.

Another look at the subjects' decisions reveals that their allocation decisions also differ by their endowment. First, we find that a significantly smaller proportion of the Set $H$ subjects, relative to the Set $M$ or Set $L$ subjects, contribute positive amounts in the public good regime (see Fig. 3 and Appendix Table B5). ${ }^{16}$ This contradicts Prediction 2(b) and cannot be explained by the income inequality-averse model. Moreover, this also cannot be explained by the differences between the Set $H$ subjects and the Set $M$ or $L$ subjects in their beliefs on the contribution decisions of the other members: the differences are not statistically significant for most of the comparisons (Appendix Table B.6). ${ }^{17}$ This result is, however, consistent with the well-known experimental evidence that subjects' allocation amounts are positively dependent on their MPCRs (e.g., Fisher et al. 1995, Zelmer 2003). The MPCR of the Set $H$ subjects (Set $L$ subjects) is the lowest (highest) as shown in Eq. (1). In addition, this is consistent with the findings of past studies showing that those vested with higher (lower) endowments cooperate less (more) in

\footnotetext{
${ }^{16}$ The levels of contributions are very similar between the three categories of the subjects in the L treatment due to the fact that one Set $H$ subject contributed his or her full endowment. The average contribution of the Set $H$ subjects (3.36) is insignificantly smaller than that of the Set $M$ subjects (6.36) or that of the Set $L$ subjects (5.32) in the H treatment.

${ }^{17}$ It implies that the less frequent positive contributions by the Set $H$ subjects cannot be explained by reciprocity models either.
} 
public goods games when their endowments are heterogeneous (e.g., Buckley and Croson 2006, Chan et al. 1996, Cherry et al. 2005, Maurice et al. 2013).

\section{Result 3: Contribution Decisions in the Public Good Regime}

The significantly smaller proportion of the Set $H$ subjects, relative to that of the Set $M$ and Set $L$ subjects, contribute positive amounts to their public accounts.

Second, the subjects under the lottery contest regime allocate the amounts that are smaller than the ones indicated in Table 1 (based on standard theory predictions under the risk neutral preference) to their lottery accounts for competition (see Appendix Table B.8). This implies that they are on average risk-averse. Despite their attempts to avoid receiving smaller payoffs in case of losing a competition by allocating smaller amounts for the contest, overall characteristics of the equilibria under risk-neutrality stay the same. We find that their allocation amounts to the lottery accounts are similar among the different subsets of the subjects (Set $H, M$ or $L$ ) in the $\mathrm{L}$ treatment. We also find that the average allocation amounts by the Set $H$ subjects (Set $L$ subjects) are the highest (lowest) in the $H$ treatment.

The distributions of realized payoffs are similar to those of perceived payoffs except for a few differences (Appendix Fig. B.1 and Table B.4). The Set $H$ subjects are materially better off in the $\mathrm{H}$ treatment if a lottery contest regime is collectively selected. By contrast, despite Result 3 , the Set $L$ subjects enjoy higher payoffs in both of the $\mathrm{L}$ and $\mathrm{H}$ treatments if a public good regime, instead of a lottery contest regime, is collectively selected.

Returning to the subjects' voting decisions, around half of the Set $H$ subjects prefer having a public good regime, rather than a lottery contest regime, in both of the main treatments (see Table 2). Thus, Result 3 seems to be a puzzle as we would reasonably expect that the subjects may behave more pro-socially if their voting decisions stem from their social preferences such as income inequality aversion. Then, what drives Result 1? Although we obtained Result 3 as in other related studies, it turns out that, except for this aspect, our subjects' collective institutional choices and behaviors are better explained by the inequality-averse model, compared with alternative hypotheses, as discussed as follows. First, we observe strong conditional cooperative behavior under the public good regime for the Set $M$ and Set $L$ subjects, as consistent with Prediction 2(c). That is, their contribution decisions are positively proportional 
to their beliefs on the (average) allocation decisions of the Set $M$ and Set $L$ subjects (see Appendix Table B.7). This resonates with the idea that subjects are income inequality-averse agents and prefer a situation with a smaller inequality in payoffs through their mutual cooperation.

\section{Result 4: Conditional Cooperation Behavior}

The contribution decisions of the Set M and Set L subjects are positively dependent on their beliefs about the (average) contribution decisions of the Set M and Set L subjects.

Second, we observe that the subjects' collective institutional choices, either a public good or a lottery contest, determine the degree of income inequality within their groups. Fig. 4(b) reports the average Gini coefficients of the subjects' realized payoffs within a group by regime in each treatment. Remarkably, the Gini coefficients in the lottery contest regime are on average $65 \%$ and $135 \%$ higher than those in the public good regime in the $\mathrm{L}$ and $\mathrm{H}$ treatments, respectively. A Mann-Whitney test finds that the former is significantly higher than the latter in each treatment (see Appendix Table B.9). The clear difference in the degree of inequality again resonates with the idea that the subjects' income inequality-averse motives drive their collective choices for a public good regime.

Third, the interpretation of our results by the subjects' income inequality-averse preferences holds even if we instead use "perceived" Gini coefficients. Each subject's "perceived" Gini coefficient can be calculated, as their believed distribution of payoffs in their group can be computed based on their own allocation decision and beliefs on the decisions of the other four members, using Eq. (1) or (2). The subjects' perceived Gini coefficients are useful especially for understanding their beliefs on inequality when making their voting decisions. A comparison of the perceived Gini coefficients between the two regimes provides a clear pattern: the average perceived Gini coefficients are significantly smaller under the public good regime in both of the L and $\mathrm{H}$ treatments (see Fig. 4(a) and Appendix Table B.9). This result well supports Prediction 2(d). 


\section{Result 5: Gini Coefficients by Regime}

Gini coefficients, whether the realized distributions of payoffs in groups or the subjects' perceived distributions of payoffs before making voting decisions, are significantly smaller under the public good regime than under the lottery contest regime in both of the L and $H$ treatments.

An alternative cause that may be responsible for the subjects' collective institutional choices, besides the inequality aversion, is their risk attitudes (see Section 3). However, our data does not support Prediction 3. The average risk attitudes ( $r$ ) are not significantly different between the supporters of a public good and those of a lottery contest for each of the Sets $H, M$ and $L$ subjects, regardless of the size of awards in the contest regime (see Appendix Table B.10). ${ }^{18}$ This suggests that it is more reasonable for us to interpret our subjects' voting decisions as their dislike for an unequal distribution of payoffs among the members.

\section{Result 6: Risk Attitudes by Treatment}

Prediction 3 does not hold. Risk Attitudes (r) are not significantly different between those who vote for a public good and those who vote for a lottery contest for each category of the subjects.

Lastly, we note that there is a possibility that the subjects' institutional choices may be affected by the effects of the endogenous process. Recent research has found that democratic decision processes may raise people's pro-social behavior through a number of ways including the effects of signals sent through voting and the democracy premium (e.g., Dal Bó et al. 2010, Tyran and Feld 2006, Kamei 2014). We could therefore expect that the presence of the endogenous process may drive their votes for the public good, assuming that some subjects have non-standard preferences and may enjoy a higher level of mutual cooperation when the public good regime is endogenously imposed. As shown in Appendix Table B.11, we find that the more the Set $M$ and $L$ subjects (the Set $L$ subjects) expect the other members to vote for a public good, the more likely they are to vote for it in the $\mathrm{L}(\mathrm{H})$ treatment. In addition, for most categories of subsets, the supporters of a public good regime contribute larger amounts, relative to the supporters of a lottery contest regime; although the differences in the average contribution are significant only for some comparisons. This suggests that some subjects may prefer to collectively implement the public good and to achieve mutual cooperation. These endogenous

\footnotetext{
${ }^{18}$ Also see Appendix Table B.1.
} 
effects alone do not explain the subjects' collective institutional choices, however. The average contribution under the public good regime is actually slightly lower in the two endogenous treatments than in the Exogenous Public Good treatment (see Fig. 3). This suggests that the effects of signals and the democracy premium are not the most important factors that drive their institutional choices in the experiment.

\section{Discussion and Conclusions}

This paper provides the first experimental evidence concerning people's collective choices between a policy that helps less-endowed to a greater degree - a public good regime and a policy that promotes competition - a competitive lottery contest regime, in a situation where the resources of individuals are unequally distributed. In the experiment, around $70 \%$ to $80 \%$ of the subjects in total prefer having a public good in their groups, contrary to the standard theory predictions. Moreover, remarkably, the subjects' preferences for the public good are little affected by the size of award in the other option, competitive lottery contest regime. A closer look at our data reveals that the subjects' institutional choices are well supported by the predictions based on income inequality-averse preferences except one aspect: the contribution decisions of the Set $H$ subjects to a public good. The distributions of payoffs within groups - not only the realized distributions but also their believed distributions before making voting decisions - are more equal for the public good regime than the lottery contest regime. Our data does not support alternative hypotheses that suggest other driving forces behind the subjects' collective institutional choices. That is, the subjects' decisions cannot be explained by their risk attitudes or the effects of the endogenous decision process.

One may wonder how people make decisions if the incentives of competition are much higher. Do they still prefer having a public good rather than a competitive lottery contest? One may suspect that our results on the subjects' institutional choices are because the awards were not large enough under the competitive lottery contest regime. One may speculate that if the return on competition is sufficiently high, then the majority of people, especially those who are willing to take risks, may choose the competitive environment. If this speculation is true, risk preferences, not income inequality aversion, may be the most important driving force behind their collective institutional choices in such environment. The advantage of the Set $H$ subjects 
particularly increases as their endowments are the highest. The Set $H$ subjects may therefore prefer a competitive lottery contest regime more if the award is sufficiently high. To gauge robustness of our main findings to a very high award under the lottery contest regime, we additionally conducted two sessions by raising the size of award from 110 to 220 while keeping all of the experimental setups in the main treatments as they are. Under the lottery contest regime with an award of 220, the equilibrium strategies based on the risk-neutral preference are: $x_{H}=50$, $x_{M}=20$ and $x_{L}=10$; and their expected payoffs are: $\pi_{H}=100, \pi_{M}=40$ and $\pi_{L}=20$. These payoffs are much higher than those in the $\mathrm{L}$ and $\mathrm{H}$ treatments (see Table 1). Notice that the subjects' strategic uncertainty in the public good regime stays the same in this additional treatment as that in the $\mathrm{L}$ and $\mathrm{H}$ treatments (the return and the degree of competition rise only in the lottery contest regime). Therefore, if people's risk aversion is an important driving force of our results, risk-loving subjects would be more likely to vote for a competitive contest in the additional treatment, compared with the $\mathrm{L}$ and $\mathrm{H}$ treatments. ${ }^{19}$ Consequently, risk attitudes must be significantly different between those who vote for the public good and those who vote for the lottery contest in this additional treatment, considering that the risk attitudes are statistically similar between them in both of the $\mathrm{L}$ and $\mathrm{H}$ treatments.

Strikingly, the subjects' voting preferences in the additional treatment are similar to those of the L and $\mathrm{H}$ treatments as shown in Appendix Table B.12. Although the proportion slightly decreases, the majority of the subjects still vote in favor of a public good. The result that around $43 \%$ of the Set $H$ subjects still vote for a public good is consistent with Bartling et al. that find people have strong aheadness-averse preferences when self-selecting their environment. Their risk attitudes, however, are not significantly different between the supporters of the public good and of the lottery contest. Although the Set $H$ subjects on average contribute a significantly smaller percentage of their endowments under the public good regime compared with the Set $L$ subjects, the Gini coefficients, whether ex-ante perceived or realized distributions of payoffs, are in fact significantly different between the two regimes. These results well support our conclusion in that the subjects' collective institutional choices in our environment are strongly driven by social preferences such as income inequality aversion.

\footnotetext{
${ }^{19}$ This should be the case even if some kind of betrayal aversion is prevalent under the public good regime. This is because the degree of the betrayal-averse motives in the additional treatment is the same as that in the $\mathrm{L}$ and $\mathrm{H}$ treatments.
} 
Lastly, our paper has two important implications regarding people's collective institutional choices. First, our study suggests that people's income inequality-averse motives may be strong enough to drive their collective institutional choices away from competitive rules. This means that a competitive scheme may not be collectively implemented in a society or an organization even though it may generate higher efficiency (i.e., a higher total payoff for a group), relative to an alternative with a public good aspect. Second, recent papers including Ertan et al. (2009), Kamei et al. (forthcoming) and Putterman et al. (2011) show that efficientlyenhanced rules that may materially benefit all members equally are more likely to be collectively selected when an equal voting rule is used because the majority of assenting votes outperform some fractions of perverse dissenting votes. Our results intriguingly finds that efficientlyenhancing competitive policies may be less likely to be imposed with an equal voting rule (compared with a weighted voting rule) when there is an alternative with a public good aspect if the population's income inequality-averse preferences are sufficiently strong and the efficiencyenhancing rule generates a greater inequality among people.

As a final remark, we note that in reality societies or organizations combine policies that promote competition and that mitigate inequality unlike our simpler setup. The mixture of different policies has been considered to be important by researchers. For example, Lazear (1989) has proposed that when relative performance evaluations of workers are used in a firm, pay inequality among them should not be too large. The competitive policy prevents the demoralization of high-skilled workers while the less unequal wage structure prevents workers from engaging in uncooperative behavior. An experimental investigation concerning how people construct institutions when both kinds of policies can be combined remains as an area for future research.

Acknowledgement: I thank Yan Chen for her hospitality in letting me conduct the experiments at University of Michigan. This project was supported by a grant-in-aid from Zengin Foundation for Studies on Economics and Finance. 


\section{References}

Akerlof, George and Janet Yellen, 1988. "Fairness and Unemployment.” American Economic Review 78(2): 44-49.

Balafoutas, Loukas, Rudolf Kerschbamer, and Matthias Sutter, 2012. "Distributional preferences and competitive behavior." Journal of Economic Behavior \& Organization 83(1): 125-135.

Bartling, Bjorn, Ernst Fehr, Michel Andre Marechal, and Daniel Schunk. 2009. "Egalitarianism and Competitiveness." American Economic Review 99(2): 93-98.

Bohnet, Irs, Fiona Greig, Benedikt Herrmann, and Richard Zeckhauser, 2008. "Betrayal Aversion: Evidence from Brazil, China, Oman, Switzerland, Turkey, and the United States.” American Economic Review 98(1): 294-310.

Bohnet, Irs, and Richard Zeckhauser, 2004. "Trust, Risk and Betrayal.” Journal of Economic Behavior \& Organization 55(4): 467-484.

Bolton, Gary E., and Axel Ockenfels, 2000. "ERC: A Theory of Equity, Reciprocity, and Competition." American Economic Review 90(1): 166-193.

Buckley, Edward, and Rachel Croson, 2006. "Income and wealth heterogeneity in the voluntary provision of linear public goods.” Journal of Public Economics 90(4-5): 935-955.

Chan, Kenneth, Stuart Mestelman, Rob Moir and Andrew Muller, 1996. "The Voluntary Provision of Public Goods under Varying Income Distributions." Canadian Journal of Economics 29(1): 54-69.

Chen, Josie I. and Kenju Kamei, 2014. "Expressing Emotion and Fairness Crowding-out in an Ultimatum Game with Incomplete Information," available at http://papers.ssrn.com/sol3/papers.cfm?abstract_id=2408496.

Cherry, Todd, Stephan Kroll and Jason Shogren, 2005. "The Impact of Endogenous Heterogeneity and Origin on Public Good Contribution: Evidence from the Lab." Journal of Economic Behavior \& Organization 57(3): 357-65. 
Dal Bó, Pedro, Andrew Foster, and Louis Putterman, 2010. "Institutions and Behavior:

Experimental Evidence on the Effects of Democracy." American Economic Review 100(5): 2205-29.

Dufwenberg, Martin and Georg Kirchsteiger, 2004. "A Theory of Sequential Reciprocity." Games and Economic Behavior 47(2): 268-298.

Ertan, Arhan, Talbot Page and Louis Putterman, 2009. "Who to punish? Individual decisions and majority rule in mitigating the free rider problem," European Economic Review 53(5): 495-511.

Falk, Armin and Urs Fischbacher, 2006. "A Theory of Reciprocity." Games and Economic Behavior 54(2): 293-315.

Fehr, Ernst, Holger Herz, and Tom Wilkening, 2013. "The Lure of Authority: Motivation and Incentive Effects of Power." American Economic Review 103(4): 1325-59.

Fehr, Ernst and Klaus M. Schmidt, 1999. "A theory of fairness, competition, and cooperation," Quarterly Journal of Economics 114(3): 817-868.

Fehr, Ernst and Klaus M. Schmidt, 2006. "The Economics of Fairness, Reciprocity and Altruism - Experimental Evidence and New Theories.” pp. 615-691 in Kolm, S.-G., Ythier, J.M. (Eds.), Handbook of the Economics of Giving, Altruism and Reciprocity. North Holland.

Fischbacher, Urs, 2007. "z-Tree: Zurich Toolbox for Ready-made Economic Experiments.” Experimental Economics 10(2): 171-178.

Fisher, Joseph, Mark Isaac, Jeffrey Schatzberg and James M. Walker, 1995. "Heterogeneous Demand for Public Goods: Behavior in the Voluntary Contributions Mechanism," Public Choice 85(3/4): 249-266.

Holt, Charles A., and Susan K. Laury, 2002. "Risk Aversion and Incentive Effects.” American Economic Review 92(5): 1644-55.

Kamei, Kenju, 2014. "Democracy and Resilient Pro-social Behavioral Change: An Experimental Study," available at http://papers.ssrn.com/sol3/papers.cfm?abstract_id=1756225. 
Kamei, Kenju, Louis Putterman, and Jean-Robert Tyran, forthcoming, "State or nature?

Endogenous formal versus informal sanctions in the voluntary provision of public goods." Experimental Economics.

Kelly, Morgan, 2000. "Inequality and Crime." Review of Economics and Statistics 82(4): 530539.

Lazear, Edward, 1989. "Pay Equality and Industrial Policies." Journal of Political Economy 97(3): 561-580.

Leech, Dennis, 2002. "Voting Power in the Governance of the International Monetary Fund." Annals of Operations Research 109(1-4): 375-97.

Markussen, Thomas, Ernesto Reuben, and Jean-Robert Tyran, 2014. "Competition, Cooperation and Collective Choice." Economic Journal 124(574): F163-F195.

Maurice, Jonathan, Agathe Rouaix and Marc Willinger, 2013. "Income Redistribution and Public Good Provision: An Experiment," International Economic Review 54 (3): 957-975.

Niederle, Muriel and Lise Vesterlund, 2007. "Do Women Shy Away From Competition? Do Men Compete Too Much?" Quarterly Journal of Economics 122(3): 1067-101.

Piketty, Thomas, 2014. Capital in the Twenty-First Century, Belknap Press.

Putterman, Louis, Jean-Robert Tyran and Kenju Kamei, 2011. "Public goods and voting on formal sanction schemes." Journal of Public Economics 95(9-10): 1213-1222.

Rabin, Matthew, 1993. "Incorporating Fairness Into Game Theory and Economics." American Economic Review 83(5): 1281-1302.

Rapkin, David, and Jonathan Strand, 2006. "Reforming the IMF's Weighted Voting System." World Economy 29(3): 305-24.

Stiglitz, Joseph, 2012. The Price of Inequality: How Today's Divided Society Endangers Our Future. W. W. Norton \& Company. 
Trevor, Charlie, Greg Reilly and Barry Gerhart, 2012. "Reconsidering Pay Dispersion's Effect on the Performance of Interdependent Work: Reconciling Sorting and Pay Inequality," Academy of Management Journal 55(3): 585-610.

Tyran, Jean-Robert, and Lar Feld, 2006, “Achieving Compliance when Legal Sanctions are Nondeterrent.” Scandinavian Journal of Economics 108(1), 135--56.

Zelmer, Jennifer, 2003, "Linear Public Goods Experiments: A Meta-Analysis.” Experimental Economics 6(3): 299-310. 
Fig. 1: Schematic Diagram of the Experimental Design

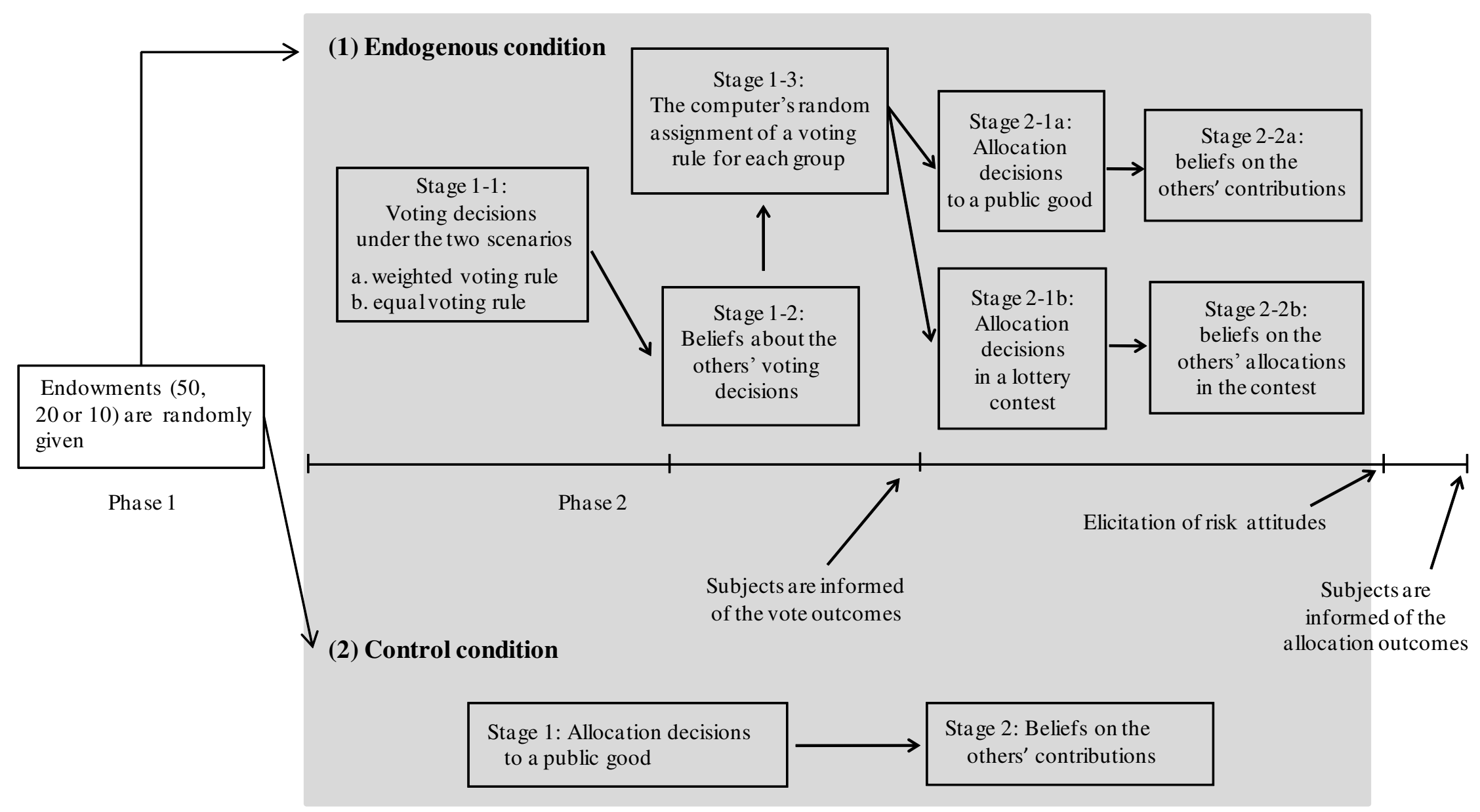


Table 1: Summary of Main Treatments

\begin{tabular}{|c|c|c|c|c|c|c|c|c|}
\hline \multirow[t]{3}{*}{ Treatment name } & \multirow{3}{*}{$\begin{array}{l}\text { Award in a } \\
\text { lottery } \\
\text { contest }\end{array}$} & \multirow{3}{*}{$\begin{array}{l}\text { Number of } \\
\text { sessions }\end{array}$} & \multirow{3}{*}{$\begin{array}{l}\text { Number } \\
\text { of groups } \\
\text { (subjects) }\end{array}$} & \multicolumn{5}{|c|}{ Standard theory predictions under the risk neutral preference } \\
\hline & & & & \multicolumn{2}{|c|}{ (a) Allocation decisions } & \multicolumn{2}{|c|}{ (b) Payoff } & \multirow{2}{*}{$\begin{array}{l}\text { (c) Voting } \\
\text { decisions }\end{array}$} \\
\hline & & & & Public good & Lottery contest & Public good & Lottery contest & \\
\hline \multicolumn{9}{|l|}{ [Main Treatments] } \\
\hline L (Low) & 50 points & 4 & $15(75)$ & $\begin{array}{c}c_{i}=0 \\
\text { for all } i\end{array}$ & $\begin{array}{c}x_{i}=8 \\
\text { for all } i\end{array}$ & $\begin{array}{l}\pi_{H}=50 \\
\pi_{M}=20 \\
\pi_{L}=10\end{array}$ & $\begin{array}{l}\pi_{H}=52 \\
\pi_{M}=22 \\
\pi_{L}=12\end{array}$ & $\begin{array}{c}\text { All members } \\
\text { vote for contest }\end{array}$ \\
\hline H (High) & 110 points & 4 & $13(65)$ & $\begin{array}{c}c_{i}=0 \\
\text { for all } i\end{array}$ & $\begin{array}{c}x_{H} \approx 21 \\
x_{M}=20, \\
\text { and } x_{L}=10 .\end{array}$ & $\begin{array}{l}\pi_{H}=50 \\
\pi_{M}=20 \\
\pi_{L}=10\end{array}$ & $\begin{aligned} \pi_{H} & =57.5 \\
\pi_{M} & =27.2 \\
\pi_{L} & =13.6\end{aligned}$ & $\begin{array}{l}\text { All members } \\
\text { vote for contest }\end{array}$ \\
\hline \multicolumn{9}{|l|}{ [Control Treatment] } \\
\hline
\end{tabular}

Notes: ${ }^{1}$ Allocations to the public account are doubled and redistributed to group members. $c_{i}$ is the contribution of subject $i$ to her public account. $x_{i}$ is the allocation of subject $i$ to her lottery account. $\pi_{H}, \pi_{M}$, and $\pi_{L}$ are the payoffs of Set $H$, Set $M$ and Set $L$ subjects, respectively. 
Table 2: Voting Decisions and Outcomes

(1) Individual Conditional Voting Decisions

\begin{tabular}{|c|c|c|c|c|c|c|}
\hline \multirow[b]{2}{*}{ Treatment } & \multirow[b]{2}{*}{ category } & & \multicolumn{2}{|c|}{ Number of Votes } & \multicolumn{2}{|c|}{ Percentage } \\
\hline & & & under $\mathrm{EV}^{1}$ & under $\mathrm{WV}^{1}$ & under EV & under WV \\
\hline \multirow[t]{8}{*}{$\mathbf{L}$ treatment } & \multirow[t]{2}{*}{ Set $H$ subjects } & Public good & 8 & 8 & $53 \%$ & $53 \%$ \\
\hline & & Lottery contest & 7 & 7 & $47 \%$ & $47 \%$ \\
\hline & \multirow[t]{2}{*}{ Set M subjects } & Public good & 23 & 21 & $77 \%$ & $70 \%$ \\
\hline & & Lottery contest & 7 & 9 & $23 \%$ & $30 \%$ \\
\hline & \multirow[t]{2}{*}{ Set $L$ subjects } & Public good & 21 & 23 & $70 \%$ & $77 \%$ \\
\hline & & Lottery contest & 9 & 7 & $30 \%$ & $23 \%$ \\
\hline & \multirow[t]{2}{*}{ Subtotal } & Public good & 52 & 52 & $69 \%$ & $69 \%$ \\
\hline & & Lottery contest & 23 & 23 & $31 \%$ & $31 \%$ \\
\hline \multirow[t]{8}{*}{$\mathbf{H}$ treatment } & \multirow[t]{2}{*}{ Set $H$ subjects } & Public good & 8 & 6 & $62 \%$ & $46 \%$ \\
\hline & & Lottery contest & 5 & 7 & $38 \%$ & $54 \%$ \\
\hline & \multirow[t]{2}{*}{ Set $M$ subjects } & Public good & 21 & 20 & $81 \%$ & $77 \%$ \\
\hline & & Lottery contest & 5 & 6 & $19 \%$ & $23 \%$ \\
\hline & \multirow[t]{2}{*}{ Set $L$ subjects } & Public good & 21 & 20 & $81 \%$ & $77 \%$ \\
\hline & & Lottery contest & 5 & 6 & $19 \%$ & $23 \%$ \\
\hline & \multirow[t]{2}{*}{ Subtotal } & Public good & 50 & 46 & $77 \%$ & $71 \%$ \\
\hline & & Lottery contest & 15 & 19 & $23 \%$ & $29 \%$ \\
\hline \multirow[t]{2}{*}{ Total } & & Public good & 102 & 98 & $73 \%$ & $70 \%$ \\
\hline & & Lottery contest & 38 & 42 & $27 \%$ & $30 \%$ \\
\hline
\end{tabular}

(2) Collective Vote Outcomes

\begin{tabular}{cccccccccc}
\hline & & \multicolumn{3}{c}{ Number of groups } & \multicolumn{3}{c}{ Percentage } \\
& & \multicolumn{2}{c}{ EV $^{1}$} & \multicolumn{2}{c}{$\mathrm{WV}^{1}$} & \multicolumn{2}{c}{ EV } & \multicolumn{2}{c}{ WV } \\
& & actual $^{2}$ & hyp. $^{3}$ & actual & hyp. & actual & hyp. & actual & hyp. \\
\hline \multirow{2}{*}{ L treatment } & Public good & 4 & 12 & 6 & 10 & $80 \%$ & $80 \%$ & $60 \%$ & $66.7 \%$ \\
& Lottery contest & 1 & 3 & 4 & 5 & $20 \%$ & $20 \%$ & $40 \%$ & $33.3 \%$ \\
H treatment & Public good & 4 & 12 & 7 & 7 & $100 \%$ & $92.3 \%$ & $78 \%$ & $53.8 \%$ \\
& Lottery contest & 0 & 1 & 2 & 6 & $0 \%$ & $7.7 \%$ & $22 \%$ & $46.2 \%$ \\
\hline \multirow{2}{*}{ Total } & Public good & 8 & 24 & 13 & 17 & $89 \%$ & $85.7 \%$ & $68 \%$ & $60.7 \%$ \\
& Lottery contest & 1 & 4 & 6 & 11 & $11 \%$ & $14.3 \%$ & $32 \%$ & $39.3 \%$ \\
\hline
\end{tabular}

Notes: ${ }^{1}$ The numbers in the EV (WV) columns in Panel (1) indicate the ones of individual voting decisions under the equal (weighted) voting rule. The numbers in the EV (WV) columns in Panel (2) indicate the ones of collective outcomes under the equal (weighted) voting rule. ${ }^{2}$ The columns labeled actual indicate realized vote outcomes in groups where the equal or weighted voting rule was randomly assigned in the experiment. ${ }^{3}$ The numbers in the hyp. columns under EV (WV) are the sums of (a) the numbers of realized collective outcomes under EV (WV) and (b) the numbers of unrealized collective outcomes based on subjects' unused votes under the EV (WV) in groups where the WV (EV) was assigned. 
Fig. 2: Average Perceived Payoffs by Endowment and Regime

(a) The L treatment

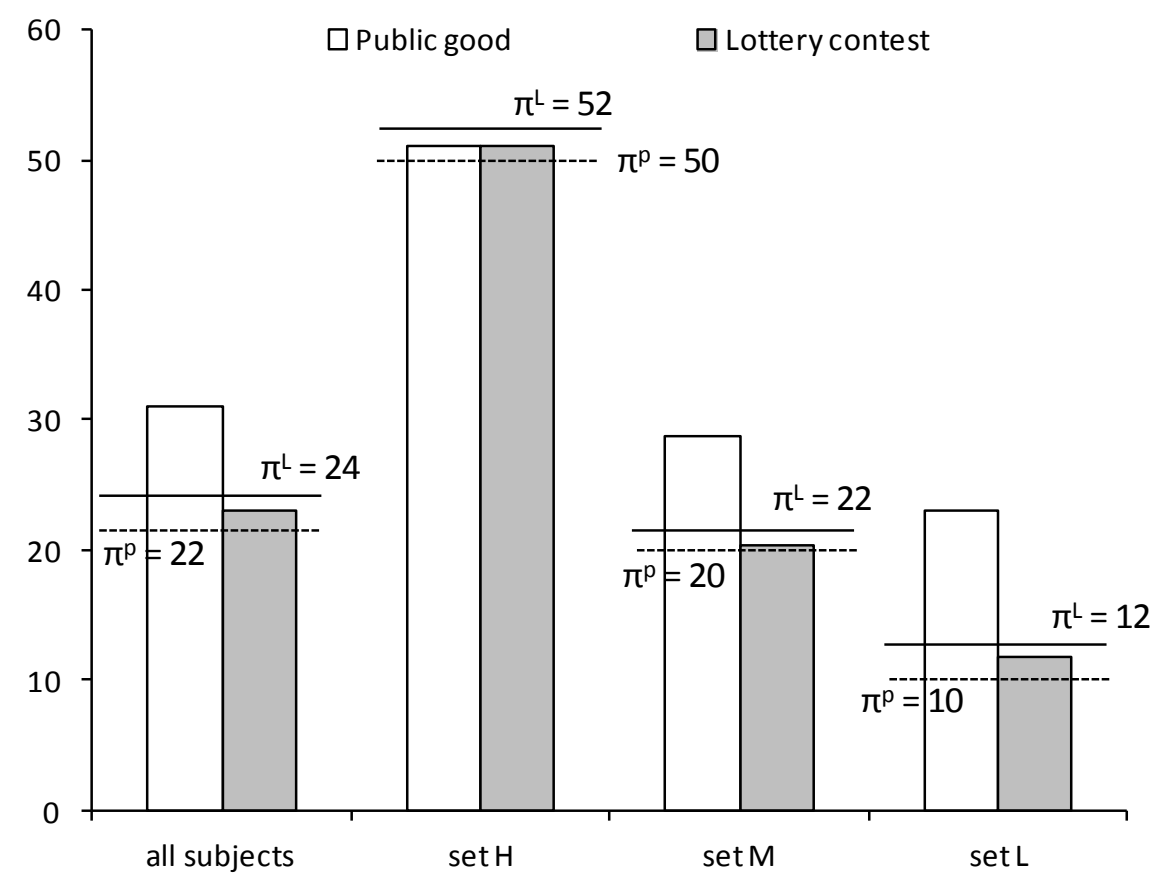

(b) The H treatment

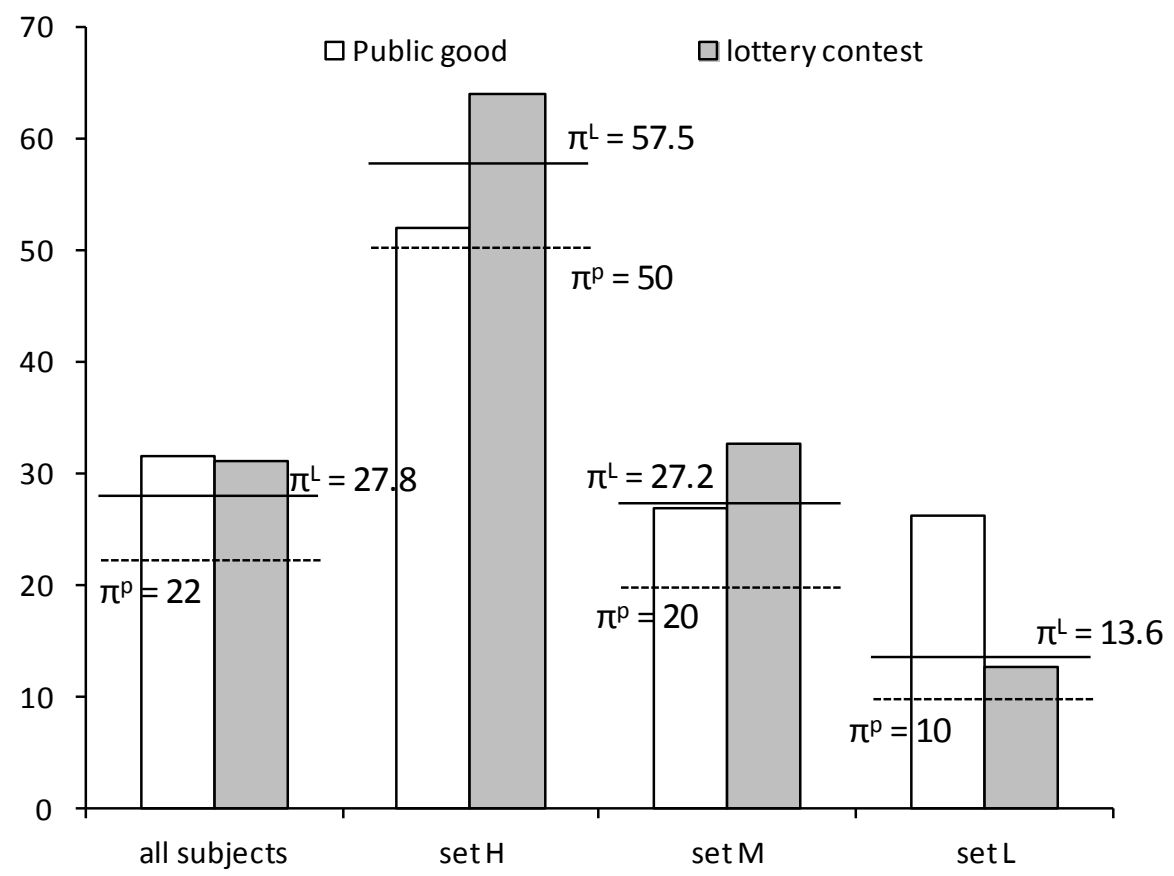

Notes: $\pi^{p}\left(\pi^{L}\right)$ are the payoffs under the public good (the lottery contest) based on the standard theory predictions with the risk-neutral preference. A subject's perceived payoff is calculated based on his or her own allocation decision and beliefs on the decisions of the other four members. The figures of average realized payoffs by endowment and regime are found in Appendix Fig. B.1. 
Fig. 3: Average Contribution Decisions in the Public Good Regime

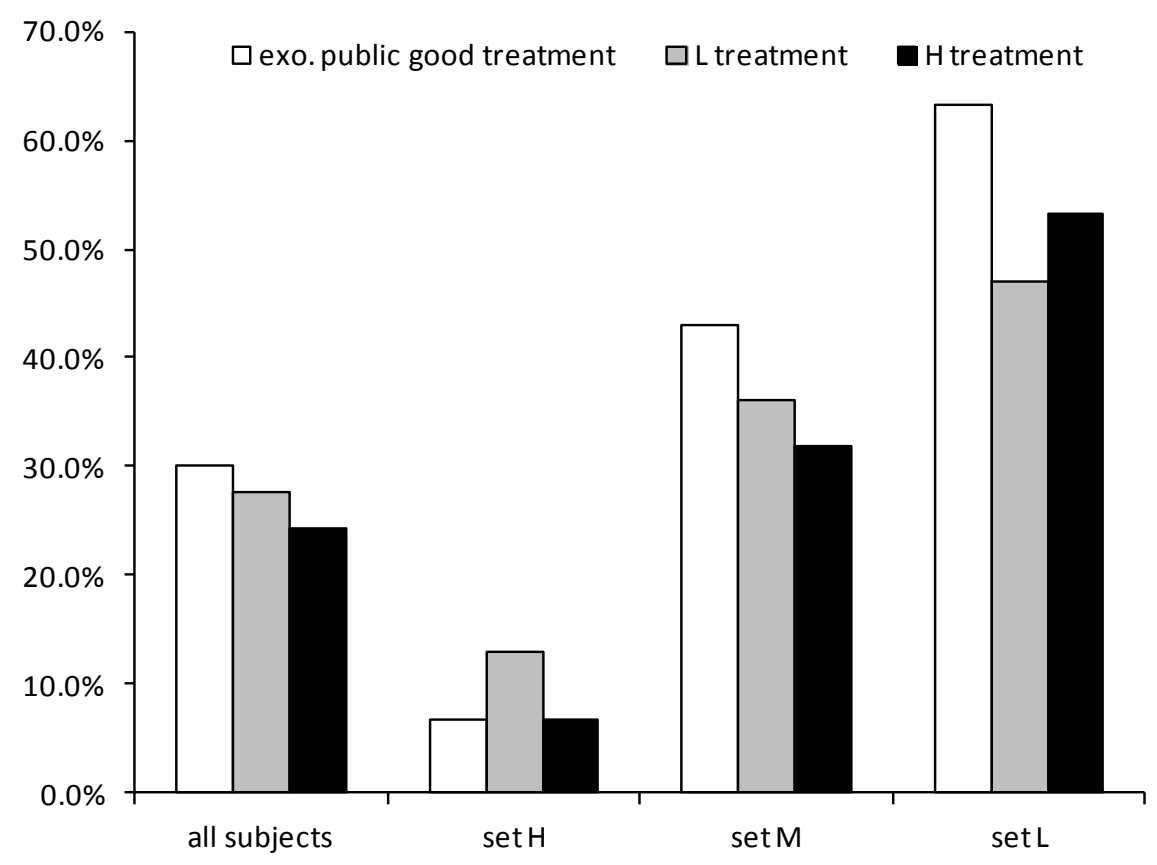

Notes: Each number in this figure is calculated by: 100.(the average contribution in the category)/(their endowments). Each of the "all subjects" bars is calculated by: 100 (the average contribution of all subjects in the corresponding treatment $) / 22$. Here, 22 is the average endowment amount $(=110 / 5)$. 
Fig. 4: Average Gini Coefficients of the Subjects' Payoffs by Regime

(a) For perceived distributions of payoffs

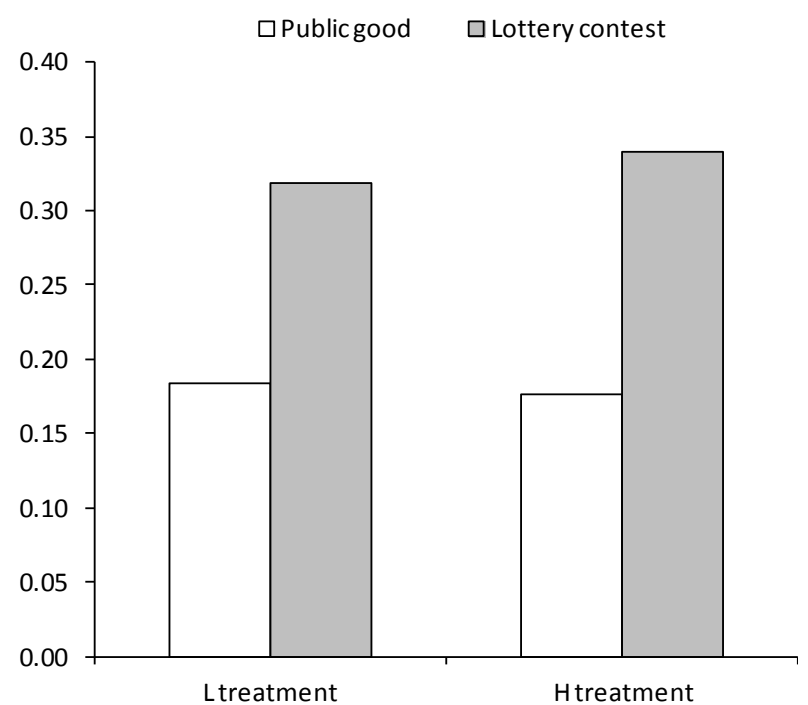

(b) For realized distributions of payoffs

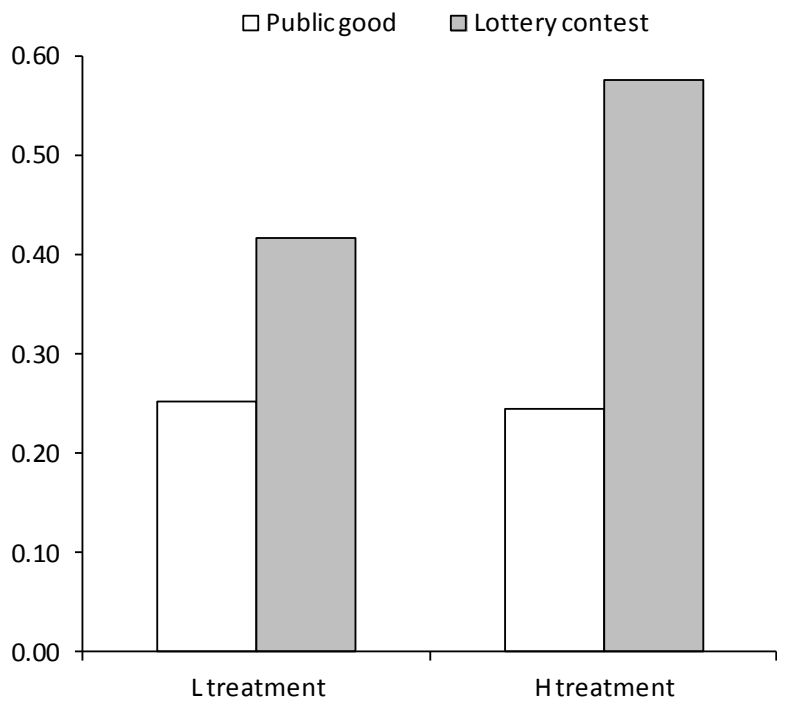

Notes: Each bar in figure (a) indicates the average perceived Gini coefficient across subjects. Specifically, we first calculated each subject's (i) own perceived payoff and (i) perceived other four members' payoffs based on his or her allocation decision and beliefs. Eq. (1) or (2) were used in calculating the payoffs. We then calculate each subject's Gini coefficient. Each bar in figure (b) indicates the average realized Gini coefficient in groups by regime. 


\section{Not for Publication}

Supplementary Online Appendix for Kamei, 2014,

“Promoting Competition or Helping Less-Endowed? Collective Institutional

Choices under Intra-Group Inequality”

Kenju Kamei

Department of Economics, Bowling Green State University, Bowling Green, OH 43403, USA.

Table of Contents

Appendix A: Theoretical Predictions $\ldots \ldots \ldots \ldots \ldots \ldots \ldots \ldots \ldots \ldots \ldots \ldots \ldots$ p. 2

Appendix B: Additional Tables and Figures $\ldots \ldots \ldots \ldots \ldots \ldots \ldots \ldots \ldots \ldots \ldots$ 


\section{Appendix A: Theoretical Predictions}

A.1. Standard Theory Predictions in the Lottery Contest Regime: Optimal Allocations under the Assumption of the Risk-Neutral Preference

a. The L treatment:

Each subject in a group maximizes his or her expected payoff expressed in Eq. (2). Suppose that the solutions are interior. Then, the first-order condition (FOC) reduces to:

$$
\frac{\partial E\left[\pi_{i}\right]}{\partial x_{i}}=-1+\frac{50 X_{-i}}{\left(x_{i}+X_{-i}\right)^{2}}=0 .
$$

Thus, each group member's best response is given by:

$$
\begin{aligned}
& -1+\frac{50\left(2 x_{M}^{*}+2 x_{L}^{*}\right)}{\left(x_{H}+2 x_{M}^{*}+2 x_{L}^{*}\right)^{2}}=0 \text { for a Set } H \text { subject. } \\
& -1+\frac{50\left(x_{H}^{*}+x_{M}^{*}+2 x_{L}^{*}\right)}{\left(x_{M}+x_{H}^{*}+x_{M}^{*}+2 x_{L}^{*}\right)^{2}}=0 \text { for a Set } M \text { subject. } \\
& -1+\frac{50\left(x_{H}^{*}+2 x_{M}^{*}+x_{L}^{*}\right)}{\left(x_{L}+x_{H}^{*}+2 x_{M}^{*}+x_{L}^{*}\right)^{2}}=0 \text { for a Set } L \text { subject. }
\end{aligned}
$$

Here, $x_{H}, x_{M}$, and $x_{L}$ are allocations to the lottery accounts by Set $H$, Set $M$ and Set $L$ subjects, respectively. Conditions (A.2) to (A.4) imply that $x_{H}^{*}=x_{M}^{*}=x_{L}^{*}=8$. Under this equilibrium, the expected payoffs of the Set $H$, Set $M$ and Set $L$ subjects are 52, 22 and 12, respectively.

There are no corner solutions. For example, suppose that $x_{L}^{*}=10, x_{M}^{*}<20$ and $x_{H}^{*}<$ 50. Then, (A.2) and (A.3) imply that $x_{H}^{*}=x_{M}^{*}$. As $\frac{\partial E\left[\pi_{L}\right]}{\partial x_{L}} \geq 0$ at $x_{L}=10$, along with condition (A.2) we get: $x_{H}^{*}>10$. However, the left hand side of condition (A.2) is negative for any $x_{H}^{*}$ such that $x_{H}^{*}>10$, contradicting that $x_{H}^{*}$ is the solution to (A.2). We likewise obtain a contradiction if we assume any other corner solution; the details are omitted to conserve space.

b. The $\mathrm{H}$ treatment:

We first show that there are no incentives for each member to change their strategy from $\left(x_{H}^{*}, x_{M}^{*}, x_{L}^{*}\right)=(21,20,10)$ in order to prove that this is an equilibrium. 
First, regarding the Set $H$ subject, all we need to check is to compare $\pi_{H}$ between two strategies: $x_{H}=21$ and $x_{H}=22$, as $\frac{\partial E\left[\pi_{H}\right]}{\partial x_{H}}=-1+\frac{110\left(2 x_{M}^{*}+2 x_{L}^{*}\right)}{\left(x_{H}+2 x_{M}^{*}+2 x_{L}^{*}\right)^{2}}=-1+\frac{110 \cdot 60}{\left(x_{H}+60\right)^{2}}$ is decreasing in $x_{H}$ and $\frac{\partial E\left[\pi_{H}\right]}{\partial x_{H}}$ is positive at $x_{H}=21$ but negative at $x_{H}=22 . x_{H}=21$ is the best strategy for the Set $H$ subject since $\left.E\left[\pi_{H}\right]\right|_{x_{H}=21, x_{M}=20, x_{L}=10}-\left.E\left[\pi_{H}\right]\right|_{x_{H}=22, x_{M}=20, x_{L}=10}=.0063$ $>0$.

Second, $x_{M}=20$ is the best response for a Set $M$ subject given that $x_{H}^{*}=21, x_{M}^{*}=20$ (the decision of the other Set $M$ subject) and $x_{L}^{*}=10$. This is because $\frac{\partial E\left[\pi_{M}\right]}{\partial x_{M}}=-1+$ $\frac{110(21+20+2 \cdot 10)}{\left(x_{M}+21+20+2 \cdot 10\right)^{2}}$ is decreasing in $x_{M}$, and $\frac{\partial E\left[\pi_{M}\right]}{\partial x_{M}}$ is positive at $x_{M}=20$.

Lastly, $x_{L}=10$ is the best response for a Set $L$ subject as well. Note that $\frac{\partial E\left[\pi_{L}\right]}{\partial x_{L}}=-1+$ $\frac{110(21+2 \cdot 20+10)}{\left(x_{L}+21+2 \cdot 20+10\right)^{2}}$ is decreasing in $x_{L}$, and $\frac{\partial E\left[\pi_{L}\right]}{\partial x_{L}}$ is positive at $x_{L}=10$.

Any other corner solution or an interior solution cannot be an equilibrium. We obtain a contradiction if we assume any other corner solution. The details are omitted to conserve space. As for the possibility of interior solutions, suppose that $x_{H}^{*}<50, x_{M}^{*}<20$ and $x_{L}^{*}<10$. Then, each group member's best response is given by:

$$
\begin{aligned}
& -1+\frac{110\left(2 x_{M}^{*}+2 x_{L}^{*}\right)}{\left(x_{H}+2 x_{M}^{*}+2 x_{L}^{*}\right)^{2}}=0 \text { for a Set } H \text { subject. } \\
& -1+\frac{110\left(x_{H}^{*}+x_{M}^{*}+2 x_{L}^{*}\right)}{\left(x_{M}+x_{H}^{*}+x_{M}^{*}+2 x_{L}^{*}\right)^{2}}=0 \text { for a Set } M \text { subject. } \\
& -1+\frac{110\left(x_{H}^{*}+2 x_{M}^{*}+x_{L}^{*}\right)}{\left(x_{L}+x_{H}^{*}+2 x_{M}^{*}+x_{L}^{*}\right)^{2}}=0 \text { for a Set } L \text { subject. }
\end{aligned}
$$

Conditions (A.5) to (A.7) imply that $x_{H}^{*}=x_{M}^{*}=x_{L}^{*}=\frac{88}{5}$. The best strategy of each subject is either 17 or 18 as $x_{H}^{*}, x_{M}^{*}$ and $x_{L}^{*}$ are integers. This contradicts the constraint that $x_{L}^{*}<10$.

At $\left(x_{H}^{*}, x_{M}^{*}, x_{L}^{*}\right)=(21,20,10)$, the expected payoffs of the Set $H$, Set $M$ and Set $L$ subjects are calculated as approximately 57.5, 27.2 and 13.6, respectively, using Eq. (2). 


\section{A.2. Predictions Based on the Income Inequality-Averse Preferences}

Suppose that the utility function of each subject is expressed as in Eq. (3). This subsection of Appendix illustrates a possibility that some subjects allocate positive amounts to their public accounts in equilibrium. For simplicity, we assume that the two Set $M$ subjects each contribute the same amounts to their public account, and that the two Set $L$ subjects also each make the same contribution decisions in equilibrium.

Proposition A1: Suppose that $\mu_{H}>\frac{1}{110}$. Also suppose that the contribution decision of a Set M subject (Set L subject) is the same as that of the other Set M subject (Set L subject). Then, some subjects in the group allocate positive amounts to their public account in equilibrium.

Proof: The utility functions of a Set $H$ subject, a Set $M$ subject and a Set $L$ subject are:

$$
\begin{aligned}
& u_{H}=\pi_{H}-\mu_{H} \cdot \frac{1}{4}\left\{2\left(\pi_{M}^{*}-\pi_{H}\right)^{2}+2\left(\pi_{L}^{*}-\pi_{H}\right)^{2}\right\} . \\
& u_{M}=\pi_{M}-\mu_{M} \cdot \frac{1}{4}\left\{\left(\pi_{H}^{*}-\pi_{M}\right)^{2}+\left(\pi_{M}^{*}-\pi_{M}\right)^{2}+2\left(\pi_{L}^{*}-\pi_{M}\right)^{2}\right\} . \\
& u_{L}=\pi_{L}-\mu_{L} \cdot \frac{1}{4}\left\{\left(\pi_{H}^{*}-\pi_{L}\right)^{2}+2\left(\pi_{M}^{*}-\pi_{L}\right)^{2}+\left(\pi_{L}^{*}-\pi_{L}\right)^{2}\right\} .
\end{aligned}
$$

Here, $\pi_{H}, \pi_{M}$, and $\pi_{L}$ are the payoffs of Set $H$, Set $M$ and Set $L$ subjects, respectively. These are expressed as in Eq. (1). $\frac{\partial u_{H}}{\partial c_{H}}, \frac{\partial u_{M}}{\partial c_{M}}$, and $\frac{\partial u_{L}}{\partial c_{L}}$, given the other subjects' strategies, are each calculated as:

$$
\begin{aligned}
& \frac{\partial u_{H}}{\partial c_{H}}=-.8+\mu_{H} \cdot\left\{88-3.13 c_{H}-.06 c_{M}^{*}+.04 c_{L}^{*}\right\} \\
& \frac{\partial u_{M}}{\partial c_{M}}=-.6-\mu_{M} \cdot\left\{1-.37 c_{H}^{*}+2.03 c_{M}-.47 c_{M}^{*}-1.04 c_{L}^{*}\right\} . \\
& \frac{\partial u_{L}}{\partial c_{L}}=-.5-\mu_{L} \cdot\left\{23-.545 c_{H}^{*}-1.29 c_{M}^{*}+1.555 c_{L}-.695 c_{L}^{*}\right\} .
\end{aligned}
$$

Here, $c_{H}, c_{M}$, and $c_{L}$ are the contributions made by a Set $H$, Set $M$ and Set $L$ subjects, respectively. Suppose that $c_{H}^{*}=c_{M}^{*}=c_{L}^{*}=0$ in equilibrium. Then, $\frac{\partial u_{H}}{\partial c_{H}}=88 \mu_{H}-.8>0$ at $c_{H}=0$, which contradicts the assumption that $c_{H}^{*}=0$ is the best response strategy for the Set $H$ subject. 
Eq. (A.8) indicates that the Set $H$ subject allocates positive amounts to his public account even if $\mu_{H}$ is relatively small. This is because the term in the curly bracket is always a large positive number (i.e., greater than 70) for any values of $c_{M}^{*}$ and $c_{L}^{*}$ when $c_{H}^{*}=0$. By contrast, Eq. (A.10) implies that only if $c_{H}^{*}$ and $c_{M}^{*}$ are high enough that $23-.545 c_{H}^{*}-1.29 c_{M}^{*}<0, \frac{\partial u_{L}}{\partial c_{L}}>0$ at $c_{L}=c_{L}^{*}=0$ for sufficiently high $\mu_{L}$. The condition $23-.545 c_{H}^{*}-1.29 c_{M}^{*}<0$ restricts the feasible set of $c_{H}^{*}$ and $c_{M}^{*}$. For example, $c_{H}^{*}=20$ and $c_{M}^{*}=8$ (each of which is $40 \%$ of his or her endowment) do not satisfy this condition. This observation suggests that more Set $H$ subjects contribute positive amounts to their public accounts than Set $L$ subjects do, provided that the distributions of individual types are the same between the Set $H$ subjects and the Set $L$ subjects.

Proposition A2: More Set H subjects contribute positive amounts to their public accounts, compared with the Set L subjects.

Eq. (A.8) to (A.10) give us a prediction concerning subjects' conditional contribution decisions in the public good regime. First, the higher $c_{H}^{*}, c_{M}^{*}$ and $c_{L}^{*}$ are, the more Set $L$ subjects contributes positive amounts to their public account. Notice that if the Set $H$ subject, the two Set $M$ subjects and the other Set $L$ subject contribute large positive amounts, then a Set $L$ subject receives relatively large payoffs, possibly payoffs even higher than the two categories of subjects in case that $c_{H}^{*}$ and $c_{M}^{*}$ are sufficiently high. More income inequality-averse Set $L$ subjects themselves then contribute positive amounts. Second, likewise, the higher $c_{H}^{*}, c_{M}^{*}$ and $c_{L}^{*}$ are, the more Set $M$ subjects contributes positive amounts to their public account. Third, conditional cooperative behavior is weak for the Set $H$ subjects. The coefficients of $c_{M}^{*}$ and $c_{L}^{*}$ are tiny in Eq. (A.8). This results from the experimental setting where the Set $H$ subjects have much higher endowments, and they have greater income inequality in their groups unless they contribute positive amounts to their public accounts. We therefore obtain the following predictions based on this consideration.

Proposition A3: The contribution amounts of the Set L subjects (the Set M subjects) are positively propositional to their beliefs on the contribution amounts of the Set H subjects, the contribution amounts of the other Set L subjects (the other Set M subjects), and the average contribution amounts of the Set M subjects (the Set L subjects). Unlike the Set M or Set L 
subjects, the contribution decisions of the Set H subjects are almost not related to the decisions of the other two categories of the subjects. 


\section{Appendix B: Additional Tables and Figures}

Fig. B.1: Average Realized Payoffs by Endowment and Regime

(a) The L treatment

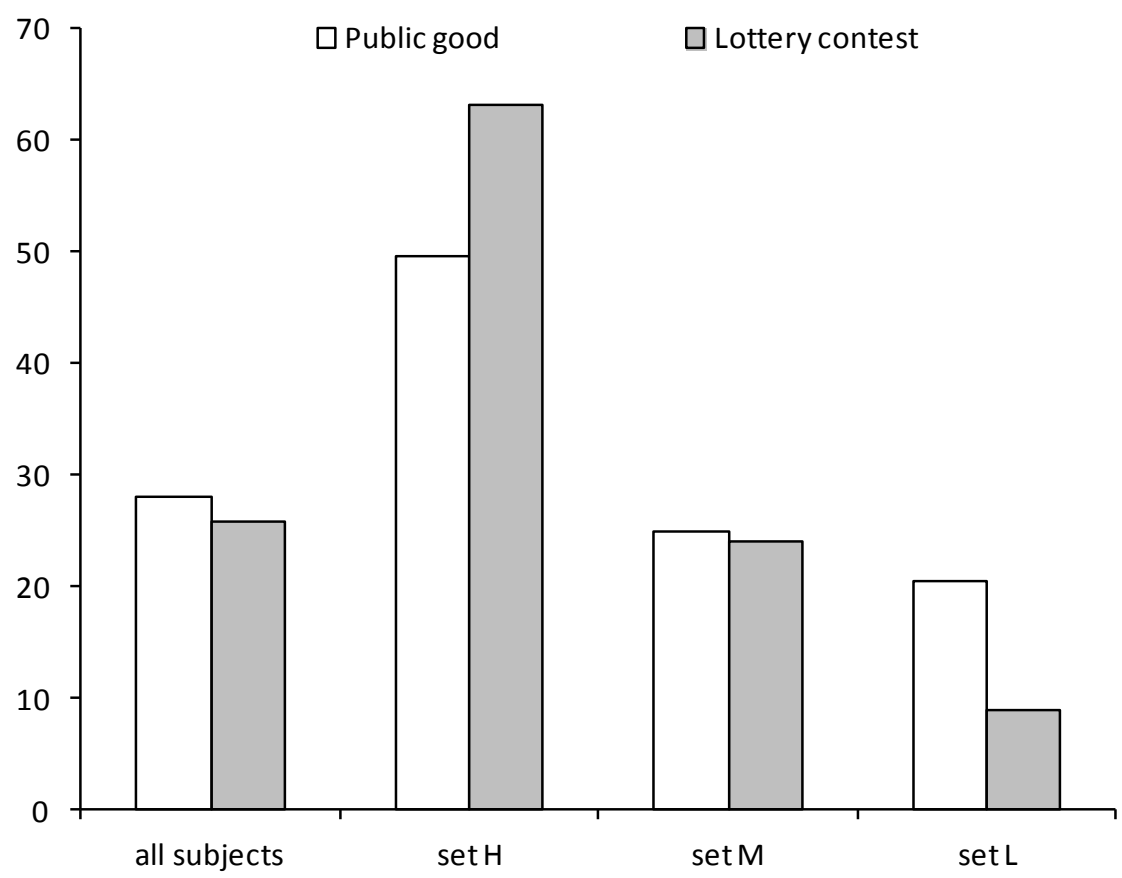

(b) The H treatment

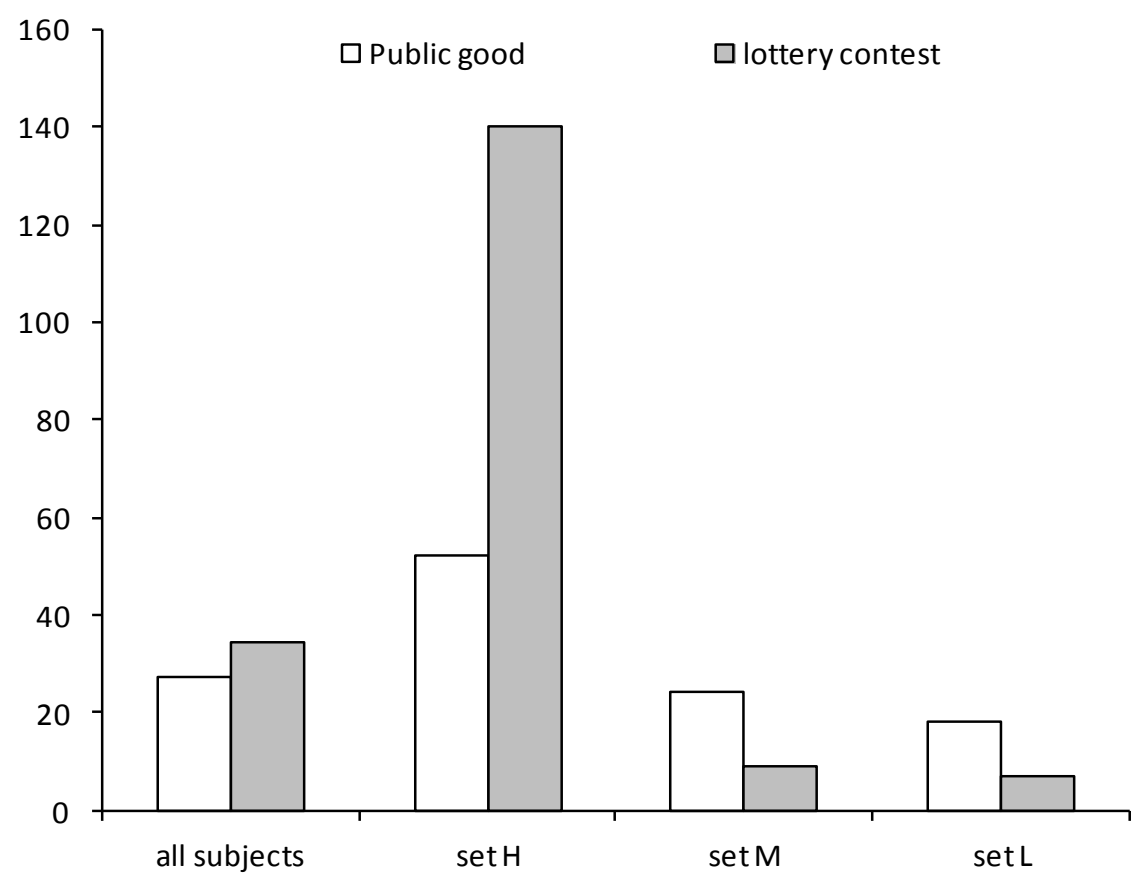


Table B.1: Determinants of Individual Votes in each Treatment (Supplementing Table 2 of the paper)

Dependent variable: A binary variable which equals 1 if a subject voted in favor of a public good under a randomly assigned voting rule; 0 otherwise.

\begin{tabular}{ccc}
\hline Independent Variable & L treatment & H treatment \\
& $(1)$ & $(2)$ \\
\hline Endowment $\in\{50,20,10\}$ & $-.022^{* *}$ & $-0.021^{*}$ \\
Risk preference, $r$ & $(0.011)$ & $(0.012)$ \\
& -.010 & -0.13 \\
Female dummy \{=1 if female; & $(0.10)$ & $(0.12)$ \\
0 otherwise $\}$ & -.005 & $.89 * *$ \\
General political orientation & $(.33)$ & $(.39)$ \\
& $-0.22^{*}$ & 0.024 \\
Constant & $(0.12)$ & $(0.16)$ \\
& $2.54 * * *$ & 1.25 \\
\# of Observations & $(0.86)$ & $(0.96)$ \\
Log likelihood & & 65 \\
LR Chi-squared & 75 & -30.82 \\
Prob $>$ LR Chi-squared & -40.65 & 8.59 \\
Pseudo R-squared & 7.65 & .0722 \\
& .1052 & .1223 \\
\hline
\end{tabular}

Notes: Probit regressions. The general political orientation variable takes an integer between 1 and $7(1=$ very conservative to $7=$ very liberal). $*$, **, and $* * *$ indicate significance at the .10 level, at the .05 level and at the .01 level, respectively. 
Table B.2: Summary of the Subjects' Perceived Payoffs in the Public Good Regime (supplementing Fig. 2 of the paper)

(a) The L treatment

\begin{tabular}{cccl}
\hline & $\begin{array}{l}\text { Total \# of } \\
\text { subjects in the } \\
\text { public good } \\
\text { regime }\end{array}$ & $\begin{array}{l}\text { \# of those whose perceived payoffs } \\
\text { in the public good regime exceed } \\
\text { their Nash Equilibrium payoffs } \\
\text { under the public good regime (50, } \\
20 \text { or 10) }\end{array}$ & $\begin{array}{l}\text { \# of those whose perceived payoffs } \\
\text { in the public good regime exceed } \\
\text { their Nash Equilibrium payoffs } \\
\text { under the lottery contest regime (52, } \\
\text { 22 or 12) }\end{array}$ \\
\hline Set $H$ subjects & 10 & $8(80.0 \%)$ & $7(70.0 \%)$ \\
Set $M$ subjects & 20 & $20(100.0 \%)$ & $19(95.0 \%)$ \\
Set $L$ subjects & 20 & $20(100.0 \%)$ & $18(90.0 \%)$ \\
Total & 50 & $48(96.0 \%)$ & $44(88.0 \%)$ \\
\hline
\end{tabular}

(b) The $\mathrm{H}$ treatment

\begin{tabular}{cccc}
\hline & $\begin{array}{l}\text { Total \# of } \\
\text { subjects in the } \\
\text { public good } \\
\text { regime }\end{array}$ & $\begin{array}{l}\text { \# of those whose perceived payoffs } \\
\text { in the public good regime exceed } \\
\text { their Nash Equilibrium payoffs } \\
\text { under the public good regime }(50, \\
20 \text { or 10) }\end{array}$ & $\begin{array}{l}\text { \# of those whose perceived payoffs } \\
\text { in the public good regime exceed } \\
\text { their Nash Equilibrium payoffs } \\
\text { under the lottery contest regime } \\
(57.5,27.5 \text { or 17.5) }\end{array}$ \\
\hline Set $H$ subjects & 11 & $9(81.8 \%)$ & $0(0.0 \%)$ \\
Set $M$ subjects & 22 & $22(100.0 \%)$ & $10(45.5 \%)$ \\
Set $L$ subjects & 22 & $22(100.0 \%)$ & $20(90.9 \%)$ \\
Total & 55 & $53(96.4 \%)$ & $30(54.5 \%)$ \\
\hline
\end{tabular}


Table B.3: Perceived Payoffs in the Public Good Regime and in the Lottery Contest Regime (supplementing Fig. 2 of the paper)

(a) The L treatment

\begin{tabular}{lcccc}
\hline & All subjects & Set $H$ subjects & Set $M$ subjects & Set $L$ subjects \\
\hline Public Good Regime $^{1}$ & $31.0(50)$ & $51.2(10)$ & $28.7(20)$ & $23.1(20)$ \\
Lottery Contest Regime $^{1}$ & $23.1(25)$ & $51.1(5)$ & $20.3(10)$ & $11.8(10)$ \\
$p$-value (two-sided) & $.0006^{* * *}$ & .2678 & $.0001 * * *$ & $.0004^{* * *}$ \\
\hline
\end{tabular}

Notes: Mann-Whitney tests. ${ }^{1}$ The numbers are average perceived payoffs. The numbers in parenthesis are the numbers of subjects. *, **, and *** indicate significance at the .10 level, at the .05 level and at the .01 level, respectively.

Results: The average perceived payoff is statistically similar between the public good regime and the lottery contest regime for the Set $H$ subjects. By contrast, the average perceived payoffs are significantly higher in the public good regime than in the lottery contest regime for the Set M subjects and the Set L subjects.

(b) The H treatment

\begin{tabular}{lcccc}
\hline & All subjects & Set $H$ subjects & Set $M$ subjects & Set $L$ subjects \\
\hline Public Good Regime $^{1}$ & $31.53(55)$ & $52.0(11)$ & $26.8(22)$ & $26.1(22)$ \\
Lottery Contest Regime $^{1}$ & $30.9(10)$ & $64.1(2)$ & $32.7(4)$ & $12.7(4)$ \\
$p$-value (two-sided) & .8060 & $.0297^{* *}$ & $.031^{* *}$ & $.0054^{* * *}$ \\
\hline
\end{tabular}

Notes: Mann-Whitney tests. ${ }^{1}$ The numbers are average perceived payoffs. The numbers in parenthesis are the numbers of subjects. *,*, and *** indicate significance at the .10 level, at the .05 level and at the .01 level, respectively.

Results: The average perceived payoffs are significantly higher in the lottery contest regime than in the public good regime for the Set $H$ subjects and the Set M subjects. By contrast, the average perceived payoff is significantly higher in the public good regime for the Set L subjects. 
Table B.4: Realized Payoffs in the Public Good Regime and in the Lottery Contest Regime (supplementing Appendix Fig. B.1 in the Appendix)

(a) The L treatment

\begin{tabular}{lcccc}
\hline & All subjects & Set $H$ subjects & Set $M$ subjects & Set $L$ subjects \\
\hline Public Good Regime $^{1}$ & $28.1(50)$ & $49.6(10)$ & $24.9(20)$ & $20.5(20)$ \\
Lottery Contest Regime $^{1}$ & $25.8(25)$ & $63.2(5)$ & $24.1(10)$ & $8.90(10)$ \\
$p$-value (two-sided) & $.0360^{* *}$ & .9021 & $.0858^{*}$ & $.0005^{* * *}$ \\
\hline
\end{tabular}

Notes: Mann-Whitney tests. ${ }^{1}$ The numbers are average realized payoffs. The numbers in parenthesis are the numbers of subjects. *,**, and $* * *$ indicate significance at the .10 level, at the .05 level and at the .01 level, respectively.

(b) The $\mathrm{H}$ treatment

\begin{tabular}{lcccc}
\hline & All subjects & Set $H$ subjects & Set $M$ subjects & Set $L$ subjects \\
\hline Public Good Regime $^{1}$ & $27.3(55)$ & $52.0(11)$ & $24.3(22)$ & $18.0(22)$ \\
Lottery Contest Regime $^{1}$ & $34.2(10)$ & $140.0(2)$ & $8.75(4)$ & $6.75(4)$ \\
$p$-value (two-sided) & $.0067 * * *$ & $.0288^{* *}$ & $.0028 * * *$ & $.0017 * * *$ \\
\hline
\end{tabular}

Notes: Mann-Whitney tests. ${ }^{1}$ The numbers are average realized payoffs. The numbers in parenthesis are the numbers of subjects. *,**, and $* * *$ indicate significance at the .10 level, at the .05 level and at the .01 level, respectively. 
Table B.5: The Difference in the Contribution Decision across the Three Categories of the Subjects in the Public Good Regime

(1) The Percentages of Subjects that Contributed Positive Amounts

\begin{tabular}{lcc}
\hline & The L treatment & The H treatment \\
\hline \multicolumn{2}{c}{ The Percentages of Subjects that Contributed Positive Amounts } \\
(i) Set $H$ subjects & $30.0 \%$ & $45.5 \%$ \\
(ii) Set $M$ subjects & $75.0 \%$ & $90.9 \%$ \\
(iii) Set $L$ subjects & $70.0 \%$ & $77.3 \%$ \\
$p$-value (two-sided) & & \\
(i) vs. (ii) & $.0177 * *$ & $.0041^{* *}$ \\
(i) vs. (iii) & $.0371 * *$ & $.0676^{*}$ \\
(ii) vs. (iii) & .7233 & .2163 \\
\hline
\end{tabular}

Notes: ${ }^{1}$ Two-sample tests of proportions. *, **, and *** indicate significance at the .10 level, at the .05 level and at the .01 level, respectively.

(2) Contribution Amounts as Percentages of their Endowments (supplementing Fig. 3 of the paper)

We compared the contribution amounts as percentages of their endowments between any two subsets of subjects (e.g., Set $H$ versus Set $L$ ) by using Mann-Whitney tests.

(2a) The L treatment

\begin{tabular}{lccc}
\hline & $\begin{array}{c}\text { Set } H \text { subjects } \\
\text { vs. Set } M \text { subjects }\end{array}$ & $\begin{array}{c}\text { Set } H \text { subjects } \\
\text { vs. Set } L \text { subjects }\end{array}$ & $\begin{array}{c}\text { Set } M \text { subjects } \\
\text { vs. Set } L \text { subjects }\end{array}$ \\
\hline$p$-value (two-sided) & $.0239^{* *}$ & $.0285^{* *}$ & .500 \\
\hline
\end{tabular}

Notes: Mann-Whitney tests. * ${ }^{* *}$, and *** indicate significance at the .10 level, at the .05 level and at the .01 level, respectively. 
(2b) The H treatment

\begin{tabular}{lccc}
\hline $\begin{array}{c}\text { Set } H \text { subjects } \\
\text { vs. Set } M \text { subjects }\end{array}$ & $\begin{array}{c}\text { Set } H \text { subjects } \\
\text { vs. Set } L \text { subjects }\end{array}$ & $\begin{array}{c}\text { Set } M \text { subjects } \\
\text { vs. Set } L \text { subjects }\end{array}$ \\
\hline$p$-value (two-sided) & $.0009 * * *$ & $.0022^{* * *}$ & $.0778^{*}$ \\
\hline
\end{tabular}

Notes: Mann-Whitney tests. *,**, and *** indicate significance at the .10 level, at the .05 level and at the .01 level, respectively.

Result: The Set H subjects on average contribute a significantly smaller fraction of their endowments to their public accounts, compared with the Set M or Set L subjects, in each of the L and $H$ treatments. The Set $M$ subjects on average contribute an insignificantly (weakly significantly) more fraction of their endowments than the Set L subjects in the L $(H)$ treatment. 
Table B.6: Average Beliefs on the Contribution Decisions of the Other Four Members in the Public Good Regime

(a) The L treatment

(a1) Average Beliefs by the Row Subjects

\begin{tabular}{lccc}
\hline & $\begin{array}{c}\text { The contribution by } \\
\text { the Set } H \text { subjects }\end{array}$ & $\begin{array}{c}\text { The (avg.) contribution } \\
\text { by the Set } M \text { subjects }\end{array}$ & $\begin{array}{c}\text { The (avg.) contribution } \\
\text { by the Set } L \text { subjects }\end{array}$ \\
\hline (i) Set $H$ subjects & --- & 9.30 & 6.60 \\
(ii) Set $M$ subjects & 10.8 & 7.95 & 6.95 \\
(iii) Set $L$ subjects & 6.50 & 9.45 & 5.50 \\
Mann-Whitney Tests ${ }^{1}$ & & & \\
(i) vs. (ii) & --- & .2142 & .5687 \\
(i) vs. (iii) & --- & .9083 & .6820 \\
(ii) vs. (iii) & .2372 & .3458 & .9521 \\
\hline
\end{tabular}

(b) The H treatment

(b1) Average Beliefs by the Row Subjects

\begin{tabular}{cccc}
\hline & $\begin{array}{c}\text { The contribution by } \\
\text { the Set } H \text { subjects }\end{array}$ & $\begin{array}{c}\text { The (avg.) contribution } \\
\text { by the Set } M \text { subjects }\end{array}$ & $\begin{array}{c}\text { The (avg.) contribution } \\
\text { by the Set } L \text { subjects }\end{array}$ \\
\hline (i) Set $H$ subjects & --- & 6.91 & 4.82 \\
(ii) Set $M$ subjects & 8.91 & 7.23 & 5.14 \\
(iii) Set $L$ subjects & 12.1 & 10.1 & 5.09 \\
Mann-Whitney Tests & --- & & .4283 \\
(i) vs. (ii) & --- & .8574 & .4149 \\
(i) vs. (iii) & .7891 & $.0561^{*}$ & .1474 \\
(ii) vs. (iii) & & $.0264^{* *}$ & \\
\hline
\end{tabular}

Notes: ${ }^{1}$ The numbers are $p$-values (two-sided). $*, * *$, and $* * *$ indicate significance at the .10 level, at the .05 level and at the .01 level, respectively. 
Table B.7: Relation between the Subjects' Contribution Decisions and their Beliefs on the Other Four Members' Contribution Decisions in the Public Good Regime

(I) The Set $H$ subjects

Dependent Variable: The contribution amount of Set $H$ subject $i$

\begin{tabular}{lcccc}
\hline & \multicolumn{2}{c}{ The $L$ treatment } & \multicolumn{2}{c}{ The $H$ treatment } \\
& $(1)$ & $(2)$ & $(4)$ & $(5)$ \\
\hline $\begin{array}{l}\text { (a) Subject } i \text { 's belief on } \\
\text { the average contribution } \\
\text { of the two Set } M \text { subjects }\end{array}$ & $2.68^{*}$ & & .66 & --- \\
& $(1.26)$ & --- & $(.49)$ & \\
(b) Subject $i$ 's belief on & & & & \\
the average contribution & ---- & 2.50 & ---- & 0.075 \\
of the two Set $L$ subjects & & $(1.98)$ & & $(0.64)$ \\
& & & & \\
Constant & -18.5 & -10.0 & -1.23 & 3.00 \\
& $(12.5)$ & $(13.9)$ & $(3.79)$ & $(3.59)$ \\
\# of observations & 10 & 10 & 11 & 11 \\
F & 4.50 & 1.59 & 1.83 & .01 \\
Prob > F & .0666 & .2430 & .2096 & .9094 \\
Adjusted R-squared & .2801 & .0614 & .0763 & -.1094 \\
& & & & \\
\hline
\end{tabular}

Notes: Linear regressions. In order to avoid a multi-colinearity issue, one of the two beliefs is used as an independent variable. The numbers in parenthesis are standard errors. *, **, and *** indicate significance at the .10 level, at the .05 level and at the .01 level, respectively. 


\section{(II) The Set $M$ subjects}

Dependent Variable: The contribution amount of Set $M$ subject $i$

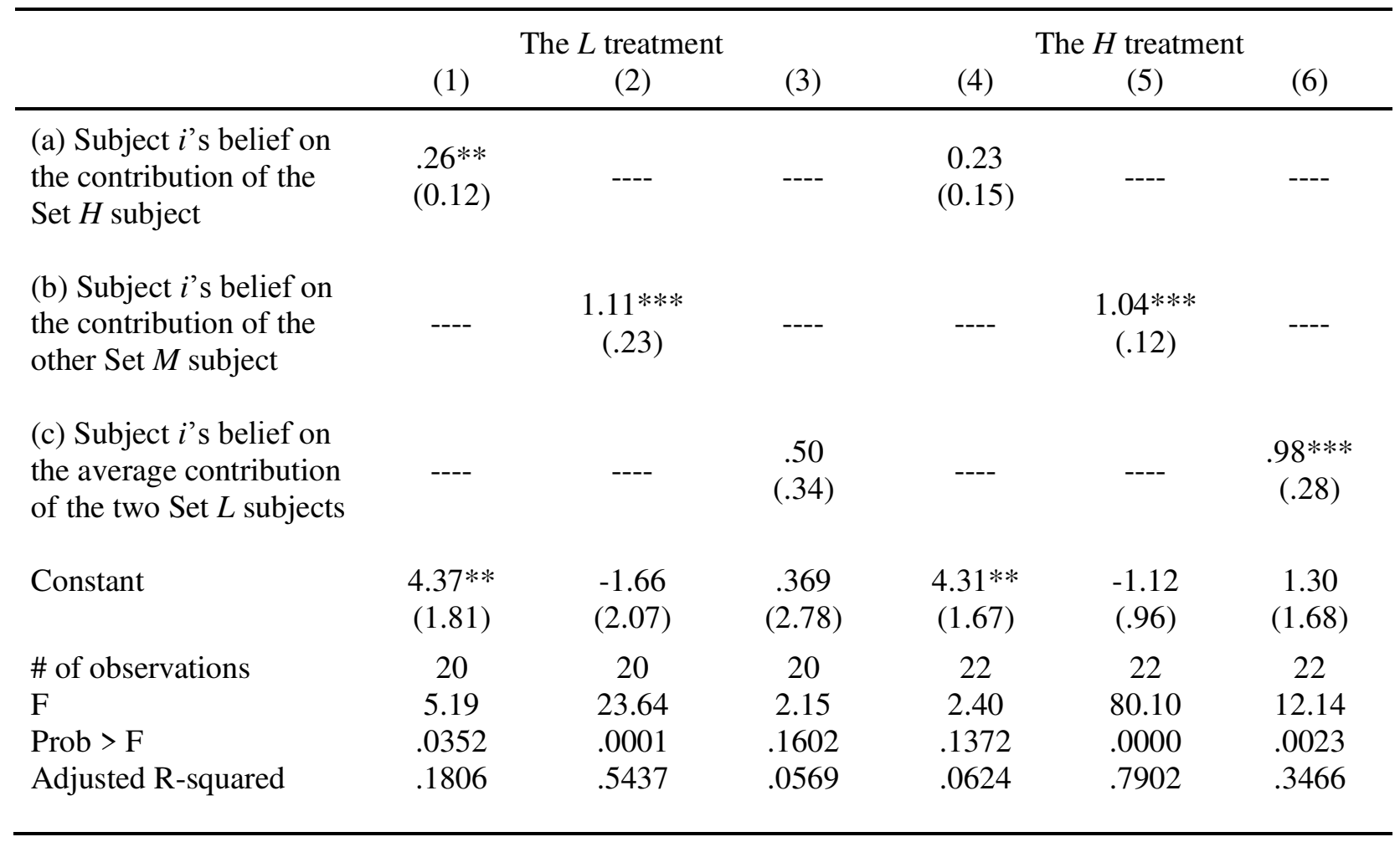

Notes: Linear regressions. In order to avoid a multi-colinearity issue, one of the three beliefs is used as an independent variable. The numbers in parenthesis are standard errors. *, **, and *** indicate significance at the .10 level, at the .05 level and at the .01 level, respectively. 
(III) The Set $L$ subjects

Dependent Variable: The contribution amount of Set $L$ subject $i$

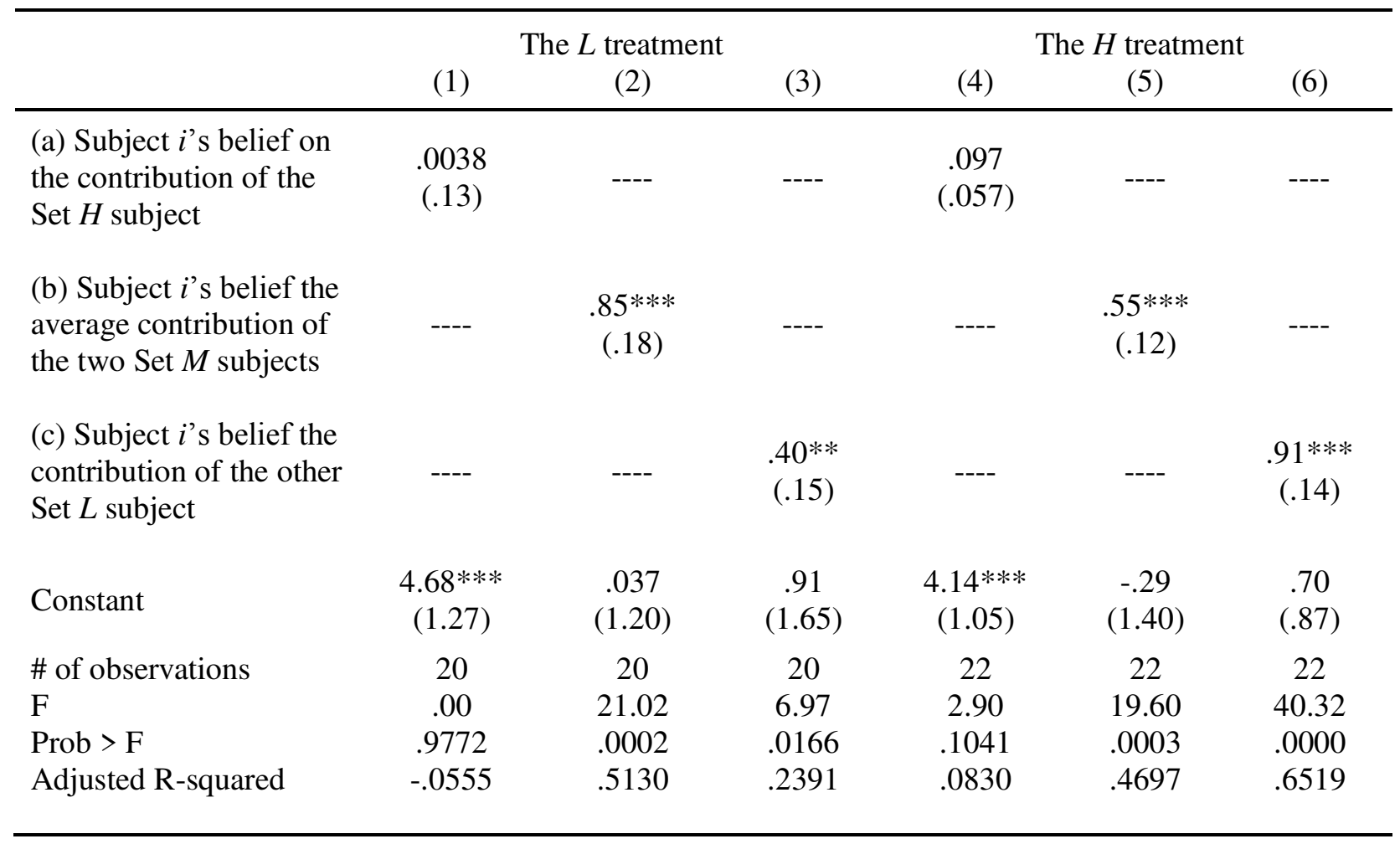

Notes: Linear regressions. In order to avoid a multi-colinearity issue, one of the three beliefs is used as an independent variable. The numbers in parenthesis are standard errors. *, **, and *** indicate significance at the .10 level, at the 0.05 level and at the .01 level, respectively. 
Table B.8: Average Allocations to the Lottery Account in the Lottery Contest Regime

\begin{tabular}{lcc}
\hline & The L Treatment & The H Treatment \\
\hline Average Allocations to the Lottery Accounts & \\
(i) Set $H$ subjects & $6.80(5)$ & $20.0(2)$ \\
(ii) Set $M$ subjects & $5.90(10)$ & $11.3(4)$ \\
(iii) Set $L$ subjects & $6.10(10)$ & $3.25(4)$ \\
Mann-Whitney Tests ${ }^{2}$ & & .1336 \\
(i) $=$ (ii) & .9011 & $.0565^{*}$ \\
(i) $=$ (iii) & .8989 & $.0796^{*}$ \\
(ii) $=$ (iii) & .8166 &
\end{tabular}

Notes: ${ }^{1}$ The numbers in parenthesis are the numbers of subjects. ${ }^{2}$ The numbers are $p$-values (two-sided). *, **, and *** indicate significance at the .10 level, at the .05 level and at the .01 level, respectively. 
Table B.9: Average Gini Coefficients by Regime (supplementing Fig. 4 of the paper and Appendix Fig. B.1)

(a) For the subjects' perceived distributions of payoffs

We first calculated (i) each subject's own perceived payoff as explained in the manuscript and (ii) the subject's perceived four group members' payoffs based on her contribution decision and beliefs about the four other members' contributions. Here, each perceived payoff in the public good regime was calculated using Eq. (1); and each perceived payoff in the lottery contest regime was calculated using Eq. (2). We then calculated a Gini coefficient for each subject.

The $\mathrm{L}$ treatment The $\mathrm{H}$ treatment

\begin{tabular}{|c|c|c|}
\hline (i) Public Good Regime ${ }^{1}$ & $.184(50)$ & $.177(55)$ \\
\hline (ii) Lottery Contest Regime ${ }^{1}$ & $.319(25)$ & $.339(10)$ \\
\hline$p$-value (two-sided) ${ }^{2}$ & $.0000 * * *$ & $.0000^{* * * *}$ \\
\hline
\end{tabular}

Notes: ${ }^{1}$ The numbers indicate the average Gini coefficients. The numbers in parenthesis indicate the numbers of subjects. ${ }^{2}$ Mann-Whitney tests for (i) $=$ (ii).

(b) For the realized distributions of payoffs within groups

We calculated a Gini coefficient for each group using the five members' realized payoffs under their collectively selected regimes.

\begin{tabular}{|c|c|c|}
\hline & The L treatment & The $\mathrm{H}$ treatment \\
\hline (i) Public Good Regime ${ }^{1}$ & $.252(10)$ & $.245(11)$ \\
\hline (ii) Lottery Contest Regime ${ }^{1}$ & $.417(5)$ & $.575(2)$ \\
\hline$p$-value (two-sided) ${ }^{2}$ & $.0022 * * *$ & $.0275 * *$ \\
\hline
\end{tabular}

Notes: ${ }^{1}$ The numbers indicate the average Gini coefficients. The numbers in parenthesis indicate the numbers of groups. ${ }^{2}$ Mann-Whitney tests for (i) = (ii). 
Table B.10: Average Risk Attitudes and Voting Decisions by Regime and Treatment

(a) The L treatment

\begin{tabular}{cccc}
\hline & Set $H$ subjects & Set $M$ subjects & Set $L$ subjects \\
\hline $\begin{array}{c}\text { (i) Those who voted for } \\
\text { a public good }\end{array}$ & 4.63 & 4.36 & 4.50 \\
(ii) Those who voted & 4.29 & $(22)$ & $(24)$ \\
for a lottery contest & $(7)$ & 5.00 & 5.17 \\
$p$-value (two-sided) & .6306 & .4748 & $(6)$ \\
\hline
\end{tabular}

(b) The H treatment

\begin{tabular}{|c|c|c|c|}
\hline & Set $H$ subjects & Set $M$ subjects & Set $L$ subjects \\
\hline $\begin{array}{l}\text { (i) Those who voted } \\
\text { for a public good }\end{array}$ & $\begin{array}{l}3.5 \\
(8)\end{array}$ & $\begin{array}{l}4.00 \\
(22)\end{array}$ & $\begin{array}{l}4.25 \\
(20)\end{array}$ \\
\hline $\begin{array}{l}\text { (ii) Those who voted } \\
\text { for a lottery contest }\end{array}$ & $\begin{array}{l}4.8 \\
(5)\end{array}$ & $\begin{array}{l}4.75 \\
(4)\end{array}$ & $\begin{array}{c}4.33 \\
(6)\end{array}$ \\
\hline$p$-value (two-sided) ${ }^{1}$ & .2290 & .5848 & 1.000 \\
\hline
\end{tabular}

Notes: ${ }^{1}$ Mann-Whitney test results for (i) $=$ (ii). The numbers are $p$-values (two-sided). $*$, **, and $* * *$ indicate significance at the .10 level, at the .05 level and at the .01 level, respectively. 
Table B.11: Voting Decisions, Beliefs on the Other Four Members' Voting Decisions and Contribution Decisions to their Public Accounts

\section{(1) Relation between the Subjects' Voting Decisions and Beliefs}

We examined how the conditional voting decisions of the subjects were dependent on their beliefs on the voting decisions of the other four members.

(1a) The L Treatment

\begin{tabular}{|c|c|c|c|c|c|c|}
\hline \multirow[b]{2}{*}{$\begin{array}{l}\text { Independent } \\
\text { Variable: }\end{array}$} & \multicolumn{3}{|c|}{$\begin{array}{l}\text { Subject } i \text { 's voting decision } \\
\text { under equal voting rule }\end{array}$} & \multicolumn{3}{|c|}{$\begin{array}{l}\text { Subject } i \text { 's voting decisions } \\
\text { under weighted voting rule }\end{array}$} \\
\hline & $\begin{array}{c}(1) \\
\text { Set } H \\
\text { subjects }\end{array}$ & $\begin{array}{c}(2) \\
\text { Set } M \\
\text { subjects }\end{array}$ & $\begin{array}{c}(3) \\
\text { Set } L \\
\text { subjects }\end{array}$ & $\begin{array}{c}(4) \\
\text { Set } H \\
\text { subjects }\end{array}$ & $\begin{array}{c}(5) \\
\text { Set } M \\
\text { subjects }\end{array}$ & $\begin{array}{c}(6) \\
\text { Set } L \\
\text { subjects }\end{array}$ \\
\hline $\begin{array}{l}\text { (a) Subject } i \text { 's belief on } \\
\text { the number of votes in } \\
\text { favor of a public good } \\
\text { under equal voting rule } \\
(\in\{0,1,2,3,4\})^{1}\end{array}$ & $\begin{array}{l}.0093 \\
(.12)\end{array}$ & $\begin{array}{l}.19 * * * \\
(.053)\end{array}$ & $\begin{array}{l}.22 * * * \\
(.071)\end{array}$ & ---- & ---- & ---- \\
\hline $\begin{array}{l}\text { (b) Subject } i \text { 's belief on } \\
\text { the number of votes in } \\
\text { favor of a public good } \\
\text { under weighted voting } \\
\text { rule }(\in\{0,1,2,3,4\})\end{array}$ & ---- & ---- & ---- & $\begin{array}{l}-.16 \\
(.17)\end{array}$ & $\begin{array}{l}.26^{* * * *} \\
(.063)\end{array}$ & $\begin{array}{l}.20 * * * \\
(.068)\end{array}$ \\
\hline Constant & $\begin{array}{c}.5 \\
(.44)\end{array}$ & $\begin{array}{l}.16 \\
(.18)\end{array}$ & $\begin{array}{c}-.046 \\
(.25)\end{array}$ & $\begin{array}{l}1.18 \\
(.70)\end{array}$ & $\begin{array}{l}-.13 \\
(.22)\end{array}$ & $\begin{array}{l}.076 \\
(.25)\end{array}$ \\
\hline \# of observations & 15 & 30 & 30 & 15 & 30 & 30 \\
\hline $\mathrm{F}$ & .01 & 12.35 & 9.66 & .90 & 16.56 & 8.48 \\
\hline Prob $>F$ & .9372 & .0015 & .0043 & .3610 & .0003 & .0070 \\
\hline Adjusted R-squared & .0005 & .2813 & .2300 & -.0075 & .3492 & .2051 \\
\hline
\end{tabular}

Notes: Linear regressions. The numbers in parenthesis indicate standard errors.

${ }^{1}$ For example, the belief of a Set $H$ subject is calculated by $N_{M}+N_{L}$. Here, $N_{M}\left(N_{L}\right)$ are the belief of the Set $H$ subject on the number of support for a public good by the Set $M$ (Set $L$ ) subjects under the equal voting rule. Here, $N_{M} \in\{0,1$, $2\}$, and $N_{L} \in\{0,1,2\}$.

$*, * *$, and $* * *$ indicate significance at the .10 level, at the .05 level and at the .01 level, respectively. 
(1b) The H Treatment

\begin{tabular}{|c|c|c|c|c|c|c|}
\hline \multirow{2}{*}{$\begin{array}{l}\text { Dependent } \\
\text { Variable: } \\
\text { Variable: }\end{array}$} & \multicolumn{3}{|c|}{$\begin{array}{l}\text { Subject } i \text { 's voting decision } \\
\text { under equal voting rule }\end{array}$} & \multicolumn{3}{|c|}{$\begin{array}{l}\text { Subject } i \text { 's voting decisions } \\
\text { under weighted voting rule }\end{array}$} \\
\hline & $\begin{array}{c}(1) \\
\text { Set } H \\
\text { subjects }\end{array}$ & $\begin{array}{c}(2) \\
\text { Set } M \\
\text { subjects }\end{array}$ & $\begin{array}{c}(3) \\
\text { Set } L \\
\text { subjects }\end{array}$ & $\begin{array}{c}(4) \\
\text { Set } H \\
\text { subjects }\end{array}$ & $\begin{array}{c}(5) \\
\text { Set } M \\
\text { subjects }\end{array}$ & $\begin{array}{c}(6) \\
\text { Set } L \\
\text { subjects }\end{array}$ \\
\hline $\begin{array}{l}\text { (a) Subject } i \text { 's belief on } \\
\text { the number of votes in } \\
\text { favor of a public good } \\
\text { under equal voting rule } \\
(\in\{0,1,2,3,4\})^{1}\end{array}$ & $\begin{array}{l}.043 \\
(.13)\end{array}$ & $\begin{array}{l}.16^{* * *} \\
(.065)\end{array}$ & $\begin{array}{l}.084 \\
(.085)\end{array}$ & --- & ---- & ---- \\
\hline $\begin{array}{l}\text { (b) Subject } i \text { 's belief on } \\
\text { the number of votes in } \\
\text { favor of a public good } \\
\text { under weighted voting } \\
\text { rule }(\in\{0,1,2,3,4\})\end{array}$ & --- & --- & --- & $\begin{array}{l}.062 \\
(.11)\end{array}$ & $\begin{array}{l}.23 * * \\
(.091)\end{array}$ & $\begin{array}{c}.11 \\
(.10)\end{array}$ \\
\hline Constant & $\begin{array}{l}.48 \\
(.42)\end{array}$ & $\begin{array}{l}.24 \\
(.24)\end{array}$ & $\begin{array}{l}.51 \\
(.31)\end{array}$ & $\begin{array}{l}.27 \\
(.36)\end{array}$ & $\begin{array}{l}-.042 \\
(.33)\end{array}$ & $\begin{array}{l}.39 \\
(.36)\end{array}$ \\
\hline \# of observations & 13 & 26 & 26 & 13 & 26 & 26 \\
\hline $\mathrm{F}$ & .12 & 5.94 & .98 & .33 & 6.38 & 1.18 \\
\hline Prob $>$ F & .7346 & .0225 & .3313 & .5754 & .0185 & .2882 \\
\hline Adjusted R-squared & -.0791 & .1651 & -.0007 & -.0588 & .1772 & .0071 \\
\hline
\end{tabular}

Notes: Linear regressions. The numbers in parenthesis indicate standard errors.

${ }^{1}$ For example, the belief of a Set $H$ subject is calculated by $N_{\mathrm{M}}+N_{\mathrm{L}}$. Here, $N_{\mathrm{M}}\left(N_{\mathrm{L}}\right)$ are the belief of the Set $H$ subject on the number of support for a public good by the Set $M$ (Set $L$ ) subjects under the equal voting rule. Here, $N_{M} \in\{0,1$, $2\}$, and $N_{L} \in\{0,1,2\}$.

$*, * *$, and $* * *$ indicate significance at the .10 level, at the .05 level and at the .01 level, respectively. 
(2) Contribution Decisions under the Public Good Regime by Voter Type

(2a) The L treatment

\begin{tabular}{lccc}
\hline & Set $H$ subjects & Set $M$ subjects & Set $L$ subjects \\
\hline $\begin{array}{l}\text { Avg. Contributions } \\
\text { (i) Those who voted for a }\end{array}$ & 8.13 & 7.13 & \\
$\begin{array}{l}\text { public good under an } \\
\text { assigned voting rule }\end{array}$ & $(8)$ & $(16)$ & 4.95 \\
$\begin{array}{l}\text { (ii) Those who voted for a } \\
\text { lottery contest under an }\end{array}$ & 0.00 & 7.50 & $(19)$ \\
assigned voting rule & $(2)$ & $(4)$ & 0.00 \\
Mann-Whitney test results for (i) $=($ ii) & & $.11)$ \\
& & & \\
p-value (two-sided $)^{1}$ & .3351 & .9234 & .2141 \\
\hline
\end{tabular}

(2b) The H treatment

\begin{tabular}{lccc}
\hline & Set $H$ subjects & Set $M$ subjects & Set $L$ subjects \\
\hline $\begin{array}{l}\text { Avg. Contributions } \\
\text { (i) Those who voted for a }\end{array}$ & 4.63 & 7.16 & \\
$\quad \begin{array}{l}\text { public good under an } \\
\text { assigned voting rule }\end{array}$ & $(8)$ & $(19)$ & 5.83 \\
$\begin{array}{l}\text { (ii) Those who voted for a } \\
\text { lottery contest under an } \\
\text { assigned voting rule }\end{array}$ & 0.00 & 1.33 & 3.00 \\
Mann-Whitney test results for (i) $=($ ii) & $(3)$ & $(3)$ & $(4)$ \\
$p$-value (two-sided) & & & \\
\hline
\end{tabular}

Notes: ${ }^{1}$ The numbers are $p$-values (two-sided). $*, * *$, and $* * *$ indicate significance at the .10 level, at the .05 level and at the .01 level, respectively. 
Table B.12: Summary of Results in the Additional Treatment

(1) Individual Conditional Voting Decisions

\begin{tabular}{cccccc}
\hline \multirow{2}{*}{ Category of subjects } & \multicolumn{2}{c}{$\begin{array}{c}\text { Number of Votes } \\
\text { under EV }\end{array}$} & \multicolumn{2}{c}{ Percentage } \\
under WV & under EV & under WV \\
\hline \multirow{2}{*}{ Set $H$ subjects } & Public good & 3 & 3 & $43 \%$ & $43 \%$ \\
& Lottery contest & 4 & 4 & $57 \%$ & $57 \%$ \\
\multirow{5}{*}{ Set $L$ subjects subjects } & Public good & 9 & 8 & $64 \%$ & $57 \%$ \\
& Lottery contest & 5 & 6 & $36 \%$ & $43 \%$ \\
& Public good & 9 & 11 & $64 \%$ & $79 \%$ \\
& Lottery contest & 5 & 3 & $36 \%$ & $21 \%$ \\
& Pubtotal good & 21 & 22 & $60 \%$ & $63 \%$ \\
& Lottery contest & 14 & 13 & $40 \%$ & $37 \%$ \\
\hline
\end{tabular}

(2) Collective Vote Outcomes

\begin{tabular}{lcccccccc}
\hline & \multicolumn{3}{c}{ Number of groups } & \multicolumn{4}{c}{ Percentage } \\
& actual $^{2}$ & hyp. $^{3}$ & actual & hyp. & actual & hyp. & actual & hyp. \\
\hline Public good & 3 & 6 & 2 & 3 & $75.0 \%$ & $85.7 \%$ & $66.7 \%$ & $42.9 \%$ \\
Lottery contest & 1 & 1 & 1 & 4 & $25.0 \%$ & $14.3 \%$ & $33.3 \%$ & $57.1 \%$ \\
\hline
\end{tabular}

Notes: ${ }^{1}$ The numbers in the EV (WV) columns in Panel (1) indicate the ones of individual voting decisions under the equal (weighted) voting rule. The numbers in the EV (WV) columns in Panel (2) indicate the ones of collective outcomes under the equal (weighted) voting rule. ${ }^{2}$ The columns labeled actual indicate vote outcomes in groups where the equal or weighted voting rule was randomly assigned in the experiment. ${ }^{3}$ The numbers in the hyp. columns under EV (WV) are the sums of (a) the numbers of realized collective outcomes under EV (WV) and (b) the numbers of unrealized collective outcomes based on subjects' unused votes under EV (WV) in groups where the WV (EV) was assigned. 
(3) Contribution Amounts as Percentages of their Endowments

(i) Set $H$ subjects

(ii) Set $M$ subjects

(iii) Set $L$ subjects

\begin{tabular}{llll}
\hline Average percentage & $4.4 \%$ & $13.0 \%$ & $75.0 \%$ \\
\hline
\end{tabular}

We compared the contribution amounts as percentages of their endowments between any two subsets of subjects (e.g., Set $H$ versus Set $L$ ) by using Mann-Whitney tests.

\begin{tabular}{lccc}
\hline & $\begin{array}{c}\text { (i) Set } H \text { subjects } \\
\text { vs. (ii) Set } M \text { subjects }\end{array}$ & $\begin{array}{c}\text { (i) Set } H \text { subjects } \\
\text { vs. (iii) Set } L \text { subjects }\end{array}$ & $\begin{array}{c}\text { (ii) Set } M \text { subjects } \\
\text { vs. (iii) Set } L \text { subjects }\end{array}$ \\
\hline$p$-value (two-sided) & .2434 & $.0090^{* * *}$ & $.0039 * * *$ \\
\hline
\end{tabular}

Notes: Mann-Whitney tests. *,**, and *** indicate significance at the .10 level, at the .05 level and at the .01 level, respectively.

(4) Average Gini Coefficients by Regime

\begin{tabular}{|c|c|c|}
\hline & $\begin{array}{c}\text { Perceived distribution } \\
\text { of payoffs }\end{array}$ & $\begin{array}{l}\text { Realized distribution } \\
\text { of payoffs }\end{array}$ \\
\hline (i) Public Good Regime & $.192(25)$ & $.281(5)$ \\
\hline (ii) Lottery Contest Regime & $.287(10)$ & $.545(2)$ \\
\hline$p$-value (two-sided $)^{1}$ & $.0176^{* *}$ & $.0528 *$ \\
\hline
\end{tabular}

Notes: Mann-Whitney test results for (i) = (ii). The numbers in parenthesis are the numbers of observations. *, **, and *** indicate significance at the .10 level, at the .05 level and at the .01 level, respectively. 
(5) Average Risk Attitudes by Voting Decision

\begin{tabular}{cccc}
\hline & Set $H$ subjects & Set $M$ subjects & Set $L$ subjects \\
\hline $\begin{array}{c}\text { (i) Those who voted for a } \\
\text { public good under an }\end{array}$ & 4.33 & 3.55 & 4.20 \\
$\quad$ assigned voting rule & $(3)$ & $(9)$ & $(10)$ \\
$\begin{array}{c}\text { (ii) Those who voted for a } \\
\text { lottery contest under an } \\
\text { assigned voting rule }\end{array}$ & 4.25 & 5.40 & 4.50 \\
$p$-value (two-sided) & $(4)$ & $(5)$ & $(4)$ \\
\hline
\end{tabular}

Notes: Mann-Whitney test results for (i) = (ii). The numbers in parenthesis are the numbers of observations. *, **, and *** indicate significance at the .10 level, at the .05 level and at the .01 level, respectively. 